\title{
Novel Nanostructured Solid Materials for Modulating Oral Drug Delivery from Solid-State Lipid-Based Drug Delivery Systems
}

\author{
Tahnee J. Dening, ${ }^{1}$ Shasha Rao, ${ }^{1}$ Nicky Thomas, ${ }^{1}$ and Clive A. Prestidge ${ }^{1,2}$
}

Received 26 June 2015; accepted 23 August 2015; published online 9 September 2015

\begin{abstract}
Lipid-based drug delivery systems (LBDDS) have gained significant attention in recent times, owing to their ability to overcome the challenges limiting the oral delivery of poorly water-soluble drugs. Despite the successful commercialization of several LBDDS products over the years, a large discrepancy exists between the number of poorly water-soluble drugs displaying suboptimal in vivo performances and the application of LBDDS to mitigate their various delivery challenges. Conventional LBDDS, including lipid solutions and suspensions, emulsions, and self-emulsifying formulations, suffer from various drawbacks limiting their widespread use and commercialization. Accordingly, solid-state LBDDS, fabricated by adsorbing LBDDS onto a chemically inert solid carrier material, have attracted substantial interest as a viable means of stabilizing LBDDS whilst eliminating some of the various limitations. This review describes the impact of solid carrier choice on LBDDS performance and highlights the importance of appropriate solid carrier material selection when designing hybrid solid-state LBDDS. Specifically, emphasis is placed on discussing the ability of the specific solid carrier to modulate drug release, control lipase action and lipid digestion, and enhance biopharmaceutical performance above the original liquid-state LBDDS. To encourage the interested reader to consider their solid carrier choice on a higher level, various novel materials with the potential for future use as solid carriers for LBDDS are described. This review is highly significant in guiding future research directions in the solid-state LBDDS field and fostering the translation of these delivery systems to the pharmaceutical marketplace.
\end{abstract}

KEY WORDS: lipid-based drug delivery systems; oral bioavailability; poorly water-soluble drugs; solid carriers; solid dosage forms.

\section{INTRODUCTION}

The ability of lipids to enhance oral absorption for poorly water-soluble drugs is well known, arising from initial observations that bioavailability of some drugs is increased when co-administered with food. Accordingly, lipid-based drug delivery systems (LBDDS) are a promising formulation strategy for many drugs exhibiting low aqueous solubility. The utility of such delivery systems is based on their ability to mimic the food (or postprandial) effect by creating a lipophilic microenvironment within the gastrointestinal tract (GIT), thereby favoring solubilization of poorly water-soluble drug molecules and providing a concentration gradient driving intestinal drug absorption processes $(1,2)$. A plethora of excellent reviews have focused on the fabrication of LBDDS and the various factors that influence biopharma-

\footnotetext{
${ }^{1}$ School of Pharmacy and Medical Sciences, University of South Australia, Adelaide, SA 5001, Australia.

${ }^{2}$ To whom correspondence should be addressed. (e-mail: clive.prestidge@unisa.edu.au)
}

ceutical performance, and the interested reader is directed to these for further information (2-7).

Despite the proven efficacy and potential of oral LBDDS as a viable formulation option for poorly water-soluble drugs, broad application of these delivery systems has not been witnessed thus far. Few LBDDS products have been successfully commercialized in recent years, and previous estimates have suggested LBDDS products command just $2-4 \%$ of the global pharmaceutical marketplace $(4,8)$. By comparison, it is estimated that $40-70 \%$ of all new drug candidates emerging from drug discovery pipelines suffer from low aqueous solubility and associated delivery challenges (9). This discrepancy highlights the significant need for further research to allow better application of LBDDS and subsequent commercialization of smarter and more efficient oral dosage forms for such poorly water-soluble drugs. Several practical limitations may be responsible for the apparent lack of application of LBDDS on a widespread commercial scale, such as high production costs, low drug loading levels, and physicochemical instability during storage (10). Consequently, solid-state LBDDS have attracted substantial interest in recent years owing to their ability to combine the well-known advantages of LBDDS with those of solid dosage forms. Solidification typically involves adsorption of LBDDS onto a chemically 
inert solid carrier material via one of several solidification techniques including physical adsorption via mixing, spraydrying, freeze-drying, rotary evaporation, melt extrusionspheronization, and melt granulation. To date, solid carrier materials for solidification of LBDDS have generally been selected based on their capacity to enable a high lipid loading efficiency, good redispersibility, and adequate tableting properties (i.e. good flowability and mechanical strength for tablet compression) (11). Whilst these characteristics are no doubt highly important, our recent studies with novel silica-lipid hybrid (SLH) microparticle formulations have demonstrated that appropriate selection of the solid carrier material and solidification technique can not only preserve the biopharmaceutical performance of the initial liquid-state LBDDS, but may further enhance performance or provide additional delivery advantages (12-15). Several researchers have successfully developed various solid-state LBDDS using a variety of solid carrier materials over the years; however, few have delved into the specific impact the solid carrier has on LBDDS performance. No solid-state LBDDS products have been commercialized as yet, possibly highlighting the need for further research/development and greater insights into these delivery systems to fast track their commercial application.

Several reviews have been devoted to the transformation of liquid-state LBDDS into solid-state systems, with a focus on the various solidification techniques available as well as the many advantages and disadvantages of LBDDS solidification $(11,16,17)$. Notably, Tan, Rao, and Prestidge wrote a recent review outlining the various solid carrier materials used for solidifying LBDDS and the potential of solid-state LBDDS to impact biopharmaceutical performance (11). The present review aims to take this discussion of solid carrier materials for LBDDS one step further, by expanding on how the specific physicochemical properties of the solid carrier material can be exploited to enhance LBDDS performance. Initially, case studies highlighting the influence of commonly used solid carriers on LBDDS properties and in vitro/in vivo performance are reviewed to specifically illustrate the vast potential of smart solid carrier excipient selection. In the following sections, various novel materials with potential as solid carriers for LBDDS are discussed. The physicochemical properties of these materials and impact on drug delivery are highlighted, and a significant effort has been made to emphasize material properties and encourage the reader to consider selecting a solid carrier on the basis of its aptitude to further advance LBDDS (e.g. provide controlled drug release, modulate lipase action and lipid digestion, and/or enhance drug loading levels), rather than simply afford a powdery LBDDS suitable for tableting or incorporation within a gelatin capsule. To the best of our knowledge, this is the first review paper to solely focus on the impact of the specific solid carrier material on oral drug delivery from LBDDS.

\section{SOLID-STATE LIPID-BASED DRUG DELIVERY SYSTEMS}

An overview of solid-state LBDDS is provided herein, with a focus on three major formulation types: dry emulsions, SLH microparticles, and solid self-(nano)emulsifying drug delivery systems (SEDDS/SNEDDS).
Dry emulsions are powdery LBDDS which can be readily reconstituted in vitro or in vivo to form oil-in-water emulsions, and thus are considered equivalent to liquid emulsions in delivering poorly water-soluble drugs (18). Precursor liquid emulsions are dispersed with a solid carrier material, and subsequent removal of the aqueous phase via a drying step results in the oil phase being encapsulated within the solid carrier. Dry emulsions are most often prepared using water-soluble solid carrier materials (i.e. polysaccharides, carbohydrates, proteins or polymers), but have also been prepared using water-insoluble silica-based materials (11). Similar to dry emulsions, SLH microparticles are a novel solid-state LBDDS fabricated from simple silica nanoparticle stabilized oil-in-water emulsions (i.e. Pickering emulsions) in a two-step process: high-pressure homogenization of emulsions and addition of silica nanoparticles, followed by spraydrying to form nanostructured SLH microparticles (15). The characteristic highly porous internal matrix structure of SLH microparticles enables various advantages for oral drug delivery, which will be expanded upon in latter sections. An alternative option, solid SEDDS/SNEDDS, may be prepared via various solidification methods, and these formulations differ most significantly from dry emulsions and SLH microparticles in terms of their initial liquid-state composition. SEDDS/SNEDDS are defined as physically stable isotropic mixtures of oil(s), surfactant(s), co-solvent(s) and solubilized drug molecules, and these systems rapidly and spontaneously form fine oil-in-water emulsions $(100-250 \mathrm{~nm})$ or nanoemulsions $(<50 \mathrm{~nm})$ following dilution and gentle agitation in aqueous media (19). The following subsections detail studies undertaken to solidify LBDDS using two of the most commonly utilized solid carrier materials: waterinsoluble silica- and silicate-based carriers and water-soluble polymeric-based carriers.

\section{Silica- and Silicate-Based Materials as Solid Carriers}

Silica- and silicate-based materials have had a longstanding traditional role in dosage form design as inert excipients given their large surface area and high adsorbing capacity $(20,21)$. Since the discovery of mesoporous silica materials (e.g. MCM-41 and SBA-15) and their first use for drug delivery by Vallet-Regi et al. in 2001, there has been an explosion of interest in silica- and silicate-based materials as delivery systems for a wide variety of hydrophilic and hydrophobic drug substances (22-24). For poorly watersoluble drugs, the specific physicochemical properties of silica- and silicate-based materials make them effective in enhancing drug dissolution and oral absorption via multiple proposed mechanisms, including (i) preservation of drug molecules in the molecularly dispersed (i.e. amorphous) form, (ii) increased drug wettability within aqueous media due to the hydrophilic nature of silica-based materials, and (iii) action as precipitation inhibitors, thereby allowing supersaturated drug solubilization which favors drug absorption (25). Of the various silica-based materials available for drug delivery, fumed silica nanoparticles (e.g. Aerosil ${ }^{\circledR}$ range), porous amorphous silica gels (e.g. Syloid ${ }^{\circledR}$ and Sylysia $\left.{ }^{\circledR}\right)$, mesoporous silica materials, and magnesium aluminum silicate (e.g. Neusilin $\left.{ }^{\circledR}\right)$ are the most important when considering oral drug delivery. For solidifying LBDDS 
specifically, fumed silica nanoparticles and magnesium aluminum silicate have been the most extensively studied materials.

\section{Silica-Lipid Hybrid Microparticles}

SLH microparticles, pioneered by the Prestidge research group, are perhaps one of the best examples of solid-state LBDDS that afford advantages over precursor LBDDS as a result of the solidification process. As their name suggests, these novel delivery systems are prepared using silica, with colloidal silicon dioxide nanoparticles being the most commonly utilized silica type (15). Penetration and/or adsorption of hydrophilic silica particles to the lipid phase during the homogenization and spray-drying processes has been proposed as the mechanism behind the formation of the specific porous matrix structure of SLH microparticles (Fig. 1). This characteristic matrix structure facilitates an enhanced rate and extent of lipid digestion, resulting from the significantly increased lipid surface area available to lipase enzymes within the GIT (14).

The ability of SLH microparticles to control lipid digestion may be exploited to optimize poorly water-soluble drug release and solubilization within the GIT. SLH microparticles were engineered using two different types of colloidal silicon dioxide (Aerosil ${ }^{\circledR} 380$ fumed silica nanoparticles, $50 \mathrm{~nm}$ aggregates composed of $7 \mathrm{~nm}$ primary particles with specific surface area $380 \mathrm{~m}^{2} \mathrm{~g}^{-1}$, and Ludox ${ }^{\circledR}$ nonporous silica nanoparticles with particle size $22 \mathrm{~nm}$ and specific surface area $140 \mathrm{~m}^{2} \mathrm{~g}^{-1}$ ) in a recent study by Tan et al. (12). At a lipid:silica ratio of 2:1 w/w, SLH microparticles prepared using Aerosil ${ }^{\circledR}$ silica were demonstrated to form spherical structures, whereas Ludox ${ }^{\circledR}$ silica produced a mixture of spherical and non-spherical particles, some with collapsed structures (Fig. 1). Confocal fluorescence microscopy provided further insight into the structures of the two SLH microparticle types, as demonstrated in Fig. 2. Aerosil ${ }^{\circledR}$ SLH microparticles possessed uniform structures with lipid droplets efficiently distributed throughout the silica matrix structure, whereas Ludox ${ }^{\circledR}$ SLH microparticles were composed of a core-shell structure with outer silica/lipid shell and with/without lipid interior, depending on morphology. This ability to engineer specific nanostructures by careful and appropriate selection of solid carriers suggests a plethora of opportunities are available to effectively control and manipulate oral poorly water-soluble drug delivery. To verify the impact of silica type on performance, in vitro lipid digestion studies were undertaken, and the specific nanostructures of the SLH microparticles were demonstrated to enhance lipid digestion kinetics in comparison with conventional lipid emulsions (Fig. 2). Both SLH microparticle formulations enhanced the rate and extent of lipid digestion in a predictable manner, with the Ludox ${ }^{\circledR}$ SLH microparticles producing a more sustained rate of lipid digestion than the Aerosil $^{\circledR}$ SLH microparticles, possibly attributable to their core-shell structure and associated shielding effects. To better understand the influence of the altered lipid digestion kinetics on poorly water-soluble drug absorption, Aerosil ${ }^{\circledR}$ SLH microparticles were evaluated in vivo in a fasted beagle dog model using celecoxib as a model poorly water-soluble drug. Whilst pure drug showed a 3-fold increase in oral bioavailability when dosed with food (containing approximately $35 \mathrm{~g}$
Precursor silica-stabilized submicron emulsions (200 nm)

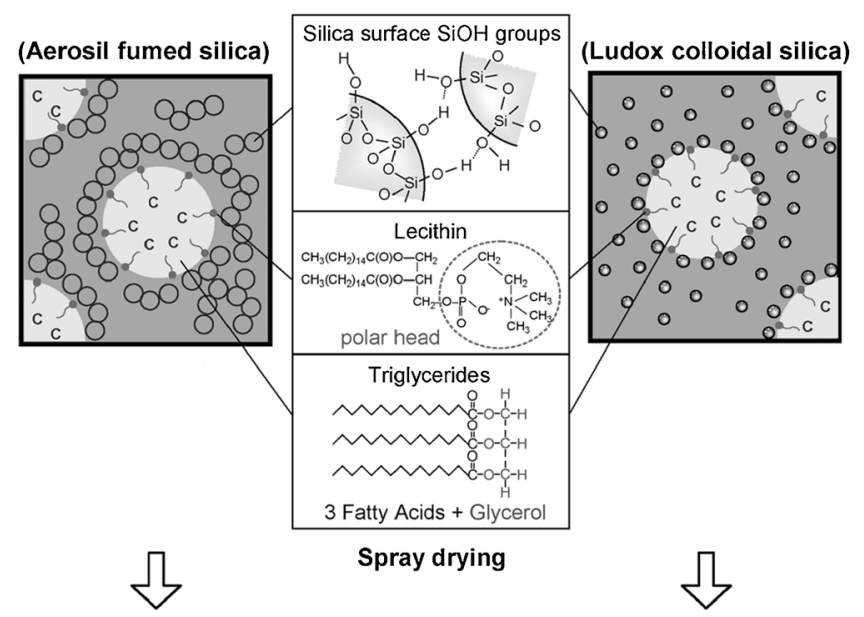

Nanostructured silica-lipid hybrid microparticles $(<10 \mu \mathrm{m})$
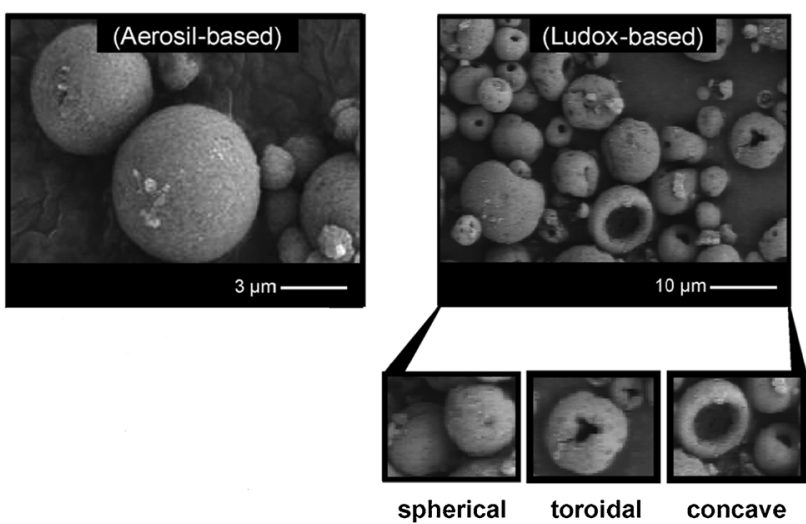

Fig. 1. Formation of nanostructured silica-lipid hybrid microparticles using two different types of silica nanoparticles: Aerosil ${ }^{\circledR}$ fumed silicon dioxide nanoparticles and Ludox ${ }^{\circledR}$ colloidal silicon dioxide nanoparticles. Different morphologies of silica-lipid hybrid microparticles achieved by altering the silica type as solid carrier are demonstrated by scanning electron microscope images. Reprinted with permission from Tan et al. (12)

fat), Aerosil ${ }^{\circledR}$ SLH microparticles (containing $<1$ g lipid) administered in the fasted-state provided a 2 -fold improvement in oral bioavailability above pure drug in the fed-state, despite the considerably lower lipid content. When compared with a conventional lipid formulation (also containing $<1 \mathrm{~g}$ lipid), SLH formulations were more efficient at enhancing drug absorption. The role of porous nanostructure in facilitating lipid digestion was therefore considered essential in optimizing formation of intestinal mixed micellar phases, into which solubilized drug molecules and digested lipids may partition prior to absorption (12).

Recent studies undertaken by Joyce et al. probed the role of nanostructure and surface chemistry in controlling the lipid digestion kinetics of medium- and long-chain triglycerides (26). Triglycerides were loaded into three types of silica from hexane: hydrophilic Aerosil ${ }^{\circledR} 380$ fumed silica nanoparticles, hydrophobic Aerosil ${ }^{\circledR}$ R812 fumed silica nanoparticles, and hydrophilic Syloid ${ }^{\circledR} 244 \mathrm{P}$ porous amorphous silica gel microparticles. Both types of hydrophilic silica enhanced lipid digestion kinetics above coarse- and submicrometerhomogenized emulsions, by increasing the lipid substrate surface area for lipase access. Aerosil ${ }^{\circledR} 380$ afforded 

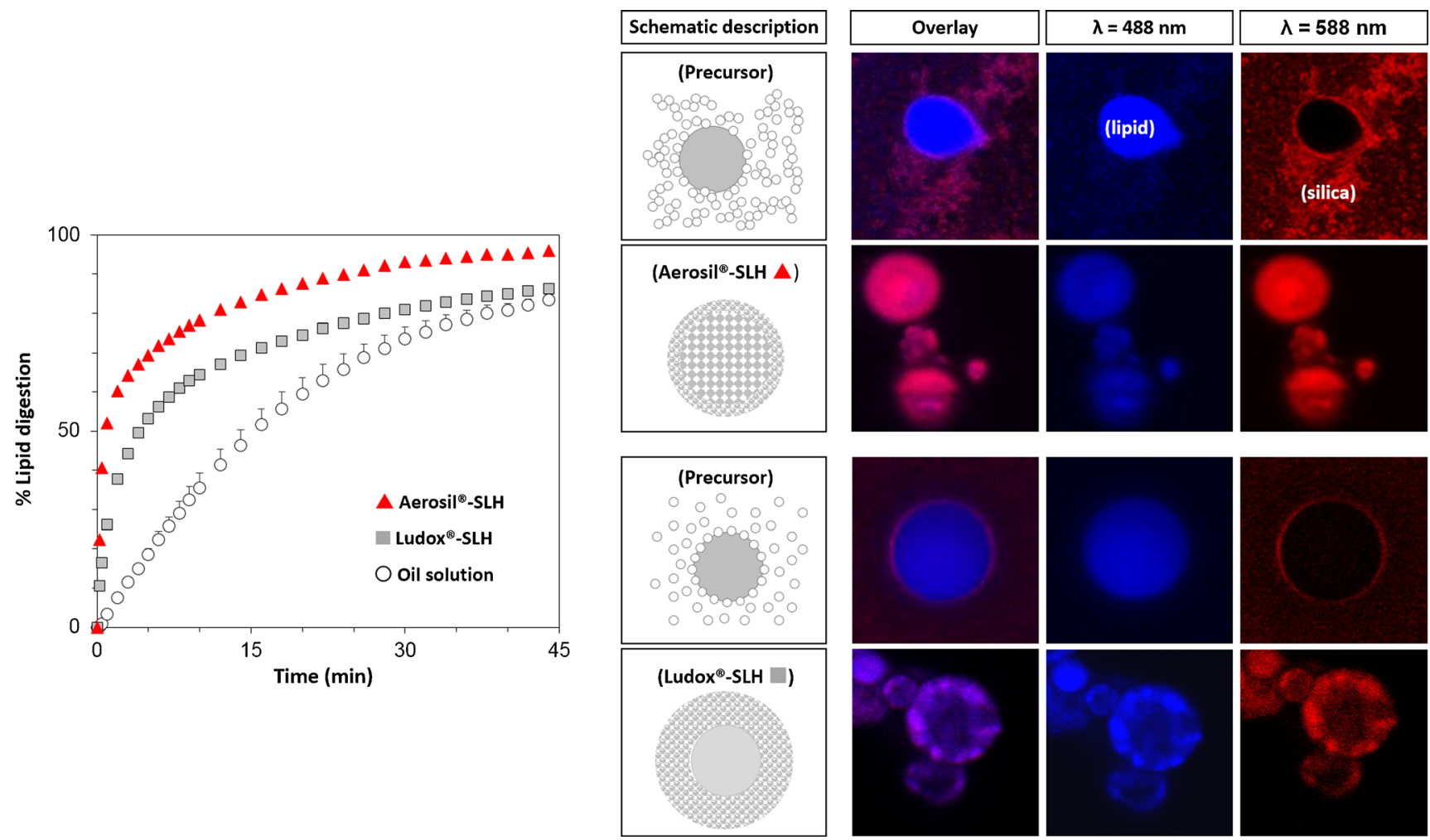

Fig. 2. Lipid digestion profiles of a simple oil solution and silica-lipid hybrid microparticles prepared using Aerosil ${ }^{\circledR}$ and Ludox ${ }^{\circledR}$ silica, respectively (left), and confocal laser scanning microscopy cross-section images of the nanostructured silica-lipid hybrid microparticles stabilized by either Aerosil ${ }^{\circledR}$ fumed silica nanoparticles or non-porous Ludox ${ }^{\circledR}$ colloidal silica where blue $=$ lipid and red $=$ silica. Modified with permission from Tan et al. (12)

improved digestion kinetics above Syloid ${ }^{\circledR} 244 \mathrm{P}$, attributed to the smaller particle/aggregate size with optimal pore size for lipase activity. Interestingly, the hydrophobic silica, Aerosil ${ }^{\circledR}$ R812, significantly reduced the extent of lipid digestion in comparison with hydrophilic silica $(13.9 \pm 0.9$ versus $100 \pm$ $0.0 \%$ after $60 \mathrm{~min}$ ). The authors proposed potential explanations, including (i) adsorption of triglyceride molecules to hydrophobic silica in an orientation that prevents the active site of lipase from accessing lipid, and (ii) hydrophobic interactions between silica and lipase, thereby exposing the hydrophilic non-catalytic domain of lipase towards the aqueous phase and lipid. Given that lipid processing is integral to poorly water-soluble drug dissolution and absorption within the GIT, consideration of the impact of the solid carrier on the rate and extent of lipid digestion is critical when designing smart hybrid solid-state LBDDS for oral drug delivery $(2,27)$.

\section{Solid Self-Emulsifying Formulations}

One of the first studies comparing the impact of the specific solid carrier on self-emulsifying formulation performance was undertaken by Kang et al. (28). For the poorly water-soluble drug flurbiprofen formulated as SNEDDS (composed of Labrafil M $1944 \mathrm{CS}^{\circledR}$, Labrasol ${ }^{\circledR}$, and Transcutol $\mathrm{HP}^{\circledR}$ ), various solid carrier materials were investigated and their impact on solid SNEDDS performance was compared $(28,29)$. Hydrophilic fumed silica nanoparticles (Aerosil $^{\circledR}$ 200), magnesium stearate, polyvinyl alcohol (PVA), sodium carboxymethylcellulose (Na-CMC), and hydroxypropyl- $\beta$-cyclodextrin (HP- $\beta-\mathrm{CD})$ were selected as solid carriers given their wide-ranging physicochemical properties. SNEDDS were spray-dried with each respective solid carrier at a SNEDDS:carrier ratio of 1:1 w/w. Marked differences in morphology were revealed via scanning electron microscope (SEM) images, with Aerosil ${ }^{\circledR}$ solid SNEDDS appearing as aggregated rough surfaced particles, indicating lipid was homogenously coated inside the pores of the Aerosil $^{\circledR}$ carrier. Whilst no comparisons were made against the original SNEDDS, in vivo studies revealed dramatic differences in area under the curve (AUC) values for solid SNEDDS fabricated with the various solid carrier materials (Fig. 3) (Table I). Aerosil ${ }^{\circledR}$ solid SNEDDS provided the highest bioavailability of flurbiprofen, and the significance of solid carrier material selection in designing optimal solid-state LBDDS was highlighted beyond doubt.

To probe further, the influence of hydrophilic (Aerosil ${ }^{\circledR}$ 200) and hydrophobic (Aerosil ${ }^{\circledR}$ R972) fumed silica nanoparticles on solid SNEDDS performance was investigated by Weerapol et al. (30). Nifedipine SNEDDS (composed of Imwitor $742^{\circledR}$, Cremophor $\mathrm{RH} 40^{\circledR}$, and Span $80^{\circledR}$ ) were solidified via physical mixing using various quantities of solid carrier (i.e. $20-50 \% w / w$ silica). The larger surface area provided by Aerosil ${ }^{\circledR} 200$ (200 versus $110 \mathrm{~m}^{2} \mathrm{~g}^{-1}$ for Aerosil $^{\circledR}$ R972) allowed for free-flowing dry powders to be obtained with up to $70 \% \mathrm{w} / \mathrm{w}$ lipid load, whereas Aerosil ${ }^{\circledR}$ R972 formed viscous oleogels when mixed with SNEDDS regardless of the silica quantity used. SEM images confirmed the smooth-surfaced gel-like appearance of Aerosil ${ }^{\circledR}$ R972 solid SNEDDS in comparison to the aggregated rough- 


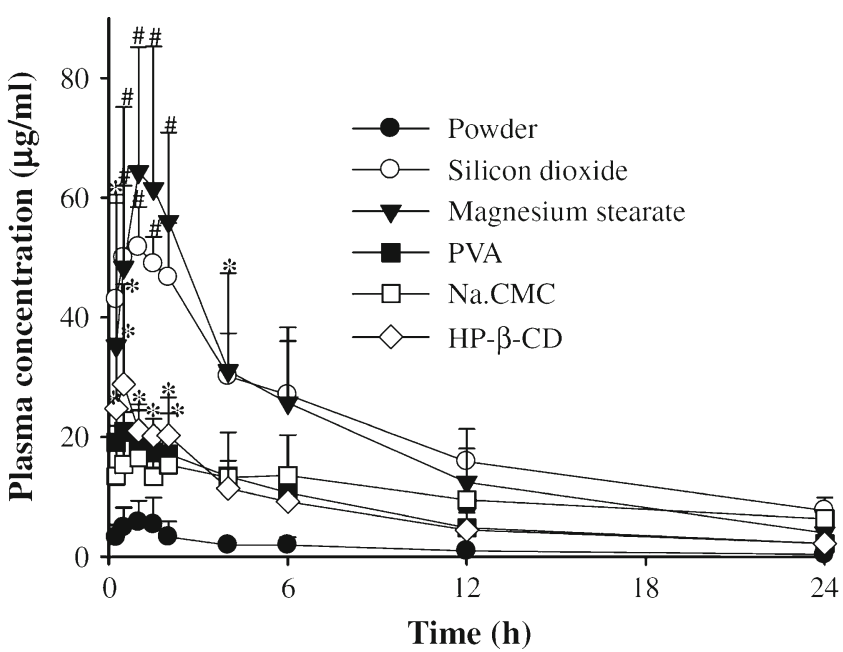

Fig. 3. Plasma concentration-time profiles of flurbiprofen following oral administration of pure drug powder and solid selfnanoemulsifying drug delivery systems solidified using various solid carrier materials. ${ }^{*} p<0.05$ compared with pure drug powder, and ${ }^{\#} p<0.05$ compared with solid self-nanoemulsifying drug delivery systems solidified with PVA, Na-CMC, and HP- $\beta-\mathrm{CD}$. Reprinted with permission from Kang et al. (28)

surfaced appearance of Aerosil $200^{\circledR}$ solid SNEDDS, indicating that surface area and hydrophobicity are important solid carrier properties to consider in forming effective solid SNEDDS. Intriguingly, all solid SNEDDS demonstrated a reduced rate and extent of in vitro drug dissolution in comparison to SNEDDS. Most significantly, when hydrophobic Aerosil ${ }^{\circledR}$ R972 was used as the solid carrier, drug dissolution was substantially lower as compared to Aerosil ${ }^{\circledR}$ 200. For solid SNEDDS prepared with a SNEDDS:silica ratio of 1:1 w/w, 32 and $80 \%$ drug dissolution was achieved after $120 \mathrm{~min}$ from solid SNEDDS fabricated using Aerosil ${ }^{\circledR}$ R972 and Aerosil ${ }^{\circledR}$ 200, respectively. Linking with the studies undertaken by Joyce et al., we might propose that hydrophobic interactions between Aerosil $^{\circledR}$ R972 and lipid excipients prompted the reduced desorption of SNEDDS and corresponding decreased drug dissolution (26). The use of hydrophobic materials as solid carriers for LBDDS clearly requires significant consideration, owing to the potential retarding effects on drug release and lipid desorption/digestion.
More recently, Van Speybroeck et al. and Williams et al. undertook detailed studies to elucidate the impact of SEDDS solidification using Neusilin ${ }^{\circledR}$ US2 (magnesium aluminum silicate granules) on the in vitro and in vivo performance of solid SEDDS (31,32). Neusilin ${ }^{\circledR}$ US2 (average particle size 44-177 $\mu \mathrm{m}$, specific surface area $300 \mathrm{~m}^{2} \mathrm{~g}^{-1}$ and average pore diameter $5-6 \mathrm{~nm}$ ) is one of the most popular solid carrier materials for self-emulsifying formulations (31). Adsorption of SEDDS onto Neusilin ${ }^{\circledR}$ US2 by physical mixing at SEDDS:Neusilin ${ }^{\circledR}$ US2 ratio of $2: 1 w / w$ noticeably reduced drug solubilization during in vitro dispersion and digestion studies (i.e. non-digesting and digesting conditions) under simulated fasted-state intestinal conditions. The percentage of drug solubilized was $35 \%$ lower from solid SEDDS compared with SEDDS, and this trend was reflected in vivo whereby solid SEDDS provided a $50 \%$ lower oral bioavailability than the original SEDDS (Fig. 4). To better understand the mechanisms behind this reduced performance, further experiments were undertaken to probe the potential cause(s). Re-adsorption of drug molecules to the Neusilin ${ }^{\circledR}$ US2 surface during dissolution was experimentally ruled out; however, incomplete desorption of surfactant molecules from Neusilin ${ }^{\circledR}$ US2 was proposed as a potential cause owing to the significantly increased nanoemulsion droplet size of solid SEDDS (i.e. 1.4- and 1.8fold increase in droplet size for solid SEDDS prepared using medium- and long-chain triglycerides, respectively). It was suggested that this reduced emulsification of SEDDS was due to high affinity of the surfactant Cremophor $\mathrm{EL}^{\circledR}$ for the Neusilin ${ }^{\circledR}$ US2 surface, and this was confirmed experimentally.

In a follow-on study by Williams et al., incomplete desorption of SEDDS from solid SEDDS solidified with Neusilin ${ }^{\circledR}$ US2 was confirmed for four poorly water-soluble drugs with various properties (i.e. danazol, fenofibrate, cinnarizine and mefenamic acid) (32). For the weak base cinnarizine and weak acid mefenamic acid, enhanced desorption from Neusilin ${ }^{\circledR}$ US2 was observed in simulated gastric fluid (SGF, $\mathrm{pH}$ 1.2) and simulated intestinal fluid (SIF, $\mathrm{pH}$ 6.5), respectively. This phenomenon was attributed to electrostatic repulsion between charged drug molecules and Neusilin ${ }^{\circledR}$ US2 surface (i.e. surface silanol groups become protonated under acidic conditions and deprotonated under basic conditions). In another study, alkaline (Neusilin ${ }^{\circledR}$ SG2, amino-functionalized) and neutral (Neusilin ${ }^{\circledR}$ US2) magnesium aluminum silicate granules were compared as solid

Table I. Summary of Pharmacokinetic Parameters for Flurbiprofen Formulated as Solid Self-Nanoemulsifying Drug Delivery Systems Using Various Solid Carrier Materials (Each Value Represents the Mean $\pm \mathrm{SD}, n=6$ )

\begin{tabular}{lllll}
\hline Solid carrier & AUC $(\mathrm{h} \mu \mathrm{g} / \mathrm{mL})$ & $C_{\max }(\mu \mathrm{g} / \mathrm{mL})$ & $T_{\max }(\mathrm{h})$ & $t_{1 / 2}(\mathrm{~h})$ \\
\hline Pure drug & $41 \pm 8$ & $5.6 \pm 3.8$ & $0.87 \pm 0.29$ & $2.11 \pm 1.99$ \\
Silicon dioxide & $609 \pm 152^{a, b}$ & $53.4 \pm 6.7^{a, b, c}$ & $0.84 \pm 0.36$ & $6.50 \pm 2.89$ \\
Magnesium stearate & $483 \pm 41^{a, b, c}$ & $64.1 \pm 17.4^{a, b, c}$ & $1.12 \pm 0.37$ & $2.31 \pm 2.39$ \\
PVA & $178 \pm 67^{a}$ & $20.9 \pm 3.4^{a}$ & $0.50 \pm 0.19$ & $7.13 \pm 2.46$ \\
Na-CMC & $451 \pm 131^{a}$ & $16.5 \pm 10.1^{a}$ & $0.72 \pm 0.95$ & $17.5 \pm 6.0^{a}$ \\
HP-B-CD & $187 \pm 83^{a}$ & $29.4 \pm 6.1^{a}$ & $0.46 \pm 0.29$ & $4.28 \pm 1.56$ \\
\hline
\end{tabular}

Reprinted with permission from Kang et al. (28)

$A U C$ area under the curve, $C_{\max }$ maximum plasma concentration, $T_{\max }$ time to maximum plasma concentration, $t_{1 / 2}$ half-life, $P V A$ polyvinyl alcohol, $\mathrm{Na}$-CMC sodium carboxymethylcellulose, $H P-\beta-C D$ hydroxypropyl- $\beta$-cyclodextrin

${ }_{b}^{a} p<0.05$ compared with pure drug powder

${ }^{b} p<0.05$ compared with PVA and HP- $\beta-C D$

${ }^{c} p<0.05$ compared with Na-CMC 


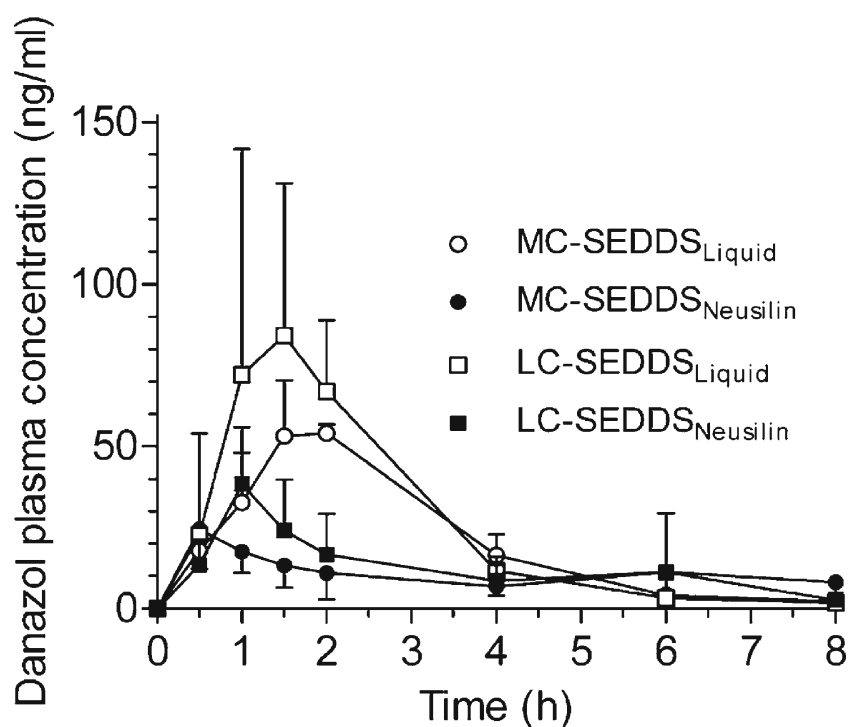

Fig. 4. Plasma concentration-time profiles for danazol following oral administration of self-emulsifying drug delivery systems and solid self-emulsifying drug delivery systems prepared using medium-chain (MC) and long-chain (LC) triglycerides to fasted rats. All rats received a dose equivalent to $3 \mathrm{mg}$ danazol. Reprinted with permission from Van Speybroeck et al. (31)

carriers for ibuprofen SEDDS (33). Similar to the previously discussed studies, adsorption of SEDDS onto Neusilin ${ }^{\circledR}$ via physical mixing reduced the extent of drug dissolution. Interestingly, however, solid SEDDS prepared using neutral Neusilin ${ }^{\circledR}$ US2 afforded a higher extent of drug dissolution in comparison to alkaline Neusilin ${ }^{\circledR} \mathrm{SG} 2$, attributed to attractive electrostatic interactions between the ibuprofen carboxylic acid group and amine groups of the alkaline solid carrier retarding drug release. Thus, whilst Neusilin ${ }^{\circledR}$ is a verified excellent solidifier of LBDDS based on its mesoporosity and large specific surface area as well as its good tabletability, these studies highlight the importance of careful consideration of the solid carrier morphology and surface chemistry to confer optimal solid SEDDS/SNEDDS performance.

\section{Polymer-Based Materials as Solid Carriers}

Polymer-based materials, including hydroxypropyl methylcellulose (HPMC), Na-CMC, polyvinylpyrrolidone (PVP), and poloxamers, have been widely applied as emulsifying agents and solid carriers for LBDDS (11). Perhaps the most useful property of this class of carrier materials is their ability to provide controlled drug release properties to pharmaceutical formulations, and this characteristic may be exploited to advantage when solidifying LBDDS. Controlled or modulated release of encapsulated drug and/or lipid excipients may be advantageous in (i) minimizing drug precipitation within the aqueous gastrointestinal (GI) environment by avoiding rapid drug release, thus promoting drug supersaturation and absorption, and (ii) prolonging therapeutic effects of drugs with short half-lives. Despite these significant advantages, an issue related to their polymeric nature is the potential to form highly viscous aqueous solutions at high concentrations; this can cause problems depending on the solidification method used $(11,18)$. Several studies have demonstrated the potential of polymer-based materials in altering LBDDS performance, and their longstanding history of use as excipients in pharmaceutical dosage forms further verifies their potential to safely optimize LBDDS.

\section{Dry Emulsions}

Oil-in-water emulsions of the poorly water-soluble drug $\mathrm{Lu}$ 28-179 were solidified using HPMC as a polymeric solid carrier, and in vivo performance was compared against a cyclodextrin inclusion-complex formulation and mediumchain triglyceride solution (34). HPMC dry emulsions were solidified via spray-drying using a lipid:HPMC ratio of 2:3 w/w, and fasted state absolute oral bioavailability in beagle dogs was found to decrease in the order of cyclodextrin solution (bioavailability 14\%), HPMC dry emulsion $(11 \%)$, and medium-chain triglyceride solution $(6 \%)$. Despite all oral formulations demonstrating low bioavailability, the HPMC dry emulsion demonstrated an approximate 2-fold bioavailability enhancement relative to the medium-chain triglyceride solution. Further, time to maximum plasma concentration $\left(T_{\max }\right)$ was prolonged by the HPMC dry emulsion compared with the medium-chain triglyceride solution ( 3.3 versus $2.0 \mathrm{~h}$ ), thus demonstrating the potential of HPMC to confer controlled release properties to solid-state LBDDS.

\section{Solid Self-Emulsifying Formulations}

HPMC has also been used as a solid carrier for SEDDS/ SNEDDS. Yi et al. developed solid SNEDDS of nimodipine using HPMC via spray-drying and compared this formulation against nimodipine spray-dried with HPMC alone, with the aim of achieving controlled drug release from both formulations (35). As shown in Fig. 5, SEM images revealed both HPMC solid SNEDDS and spray-dried HPMC matrix formulations to exhibit a regular spherical shape; however, the solid SNEDDS had a rougher surface with many pores present (pore size $<100 \mathrm{~nm}$ ). Controlled drug release was obtained for both formulation types during in vitro release studies (Fig. 5). As expected, polymer viscosity had a marked influence on drug release rate, with higher viscosity HPMC providing slower release rates. Diffusion, swelling, and polymer erosion are the most important drug release mechanisms when considering HPMC, and for the spraydried HPMC matrix formulations, polymer erosion is the dominant mechanism behind drug release. For solid SNEDDS, faster drug release rates were obtained, and this was attributed to potential diffusion of SNEDDS from the porous HPMC matrices upon dispersion in aqueous media. Notably, continuous drug release from solid SNEDDS was measured up to $8 \mathrm{~h}$, significantly different from that characteristically seen with self-emulsifying formulations, whereby maximum drug release is often achieved in a matter of minutes.

An alternative to HPMC, Na-CMC, was used to solidify SNEDDS of flurbiprofen in a study undertaken by Kang et al. (28). In comparison to various other solid carrier materials, the Na-CMC solid SNEDDS prepared via spray-drying formed roughly spherical particles with irregular and crushed shapes and significantly increased the nanoemulsion droplet 


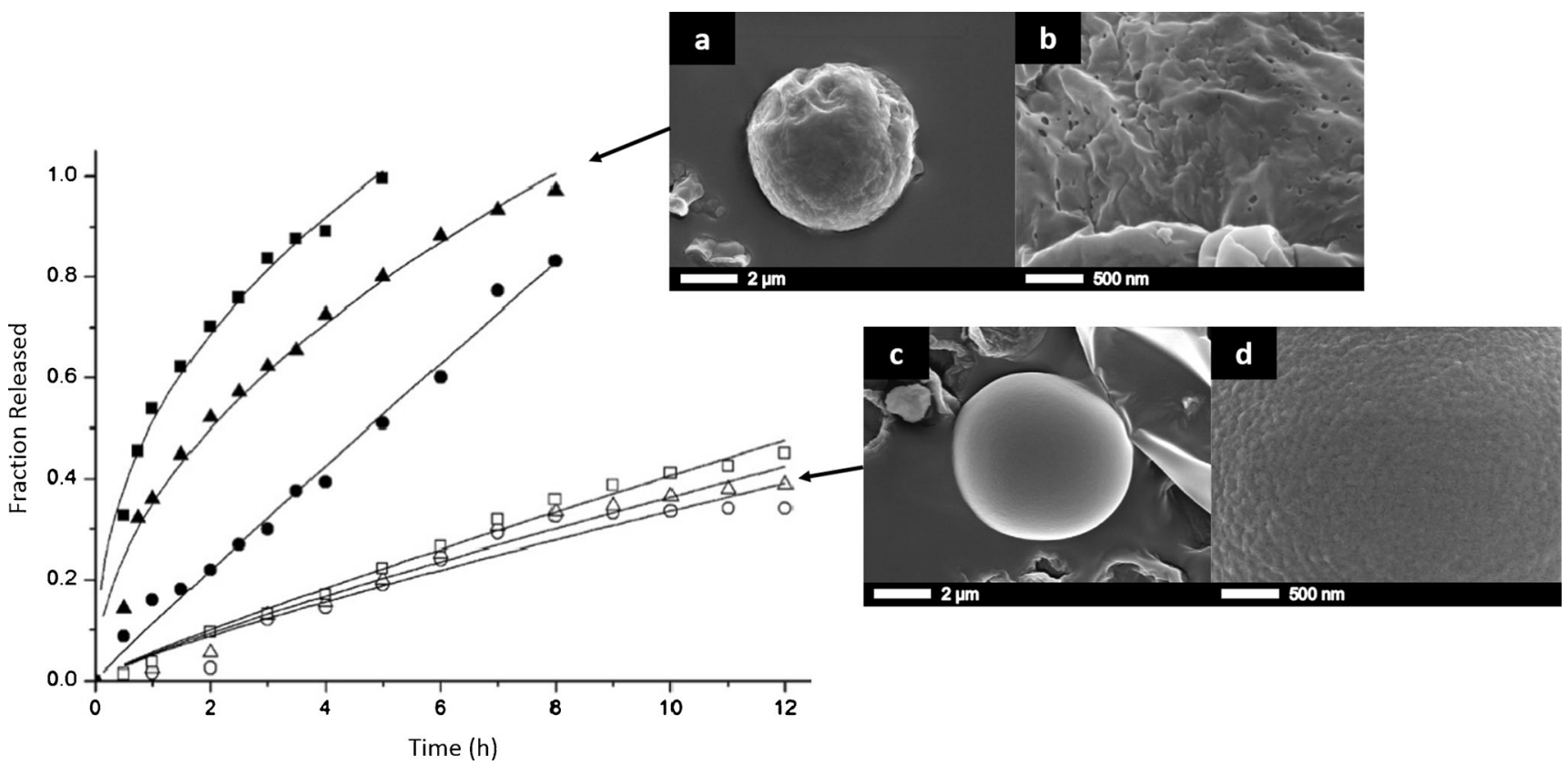

Fig. 5. In vitro dissolution profiles of hydroxypropyl methylcellulose solid self-nanoemulsifying drug delivery systems (represented by solid symbols) and spray-dried hydroxypropyl methylcellulose matrix formulations (represented by empty symbols) in $900 \mathrm{~mL}$ acetate buffer ( $\mathrm{pH} 4.5$ ) containing $0.05 \% \mathrm{w} / \mathrm{v}$ sodium dodecyl sulfate at $37^{\circ} \mathrm{C}$. Inset: scanning electron microscope images of hydroxypropyl methylcellulose solid self-nanoemulsifying drug delivery systems where $\mathbf{a}$ whole particle and $\mathbf{b}$ surface and hydroxypropyl methylcellulose matrix where $\mathbf{c}$ whole particle and $\mathbf{d}$ surface. Reprinted with permission from Yi et al. (35)

size following redispersion when compared with the original SNEDDS $(910 \pm 20$ versus $101 \pm 4 \mathrm{~nm})$. In vitro dissolution studies were undertaken in water, and although the Na-CMC solid SNEDDS was unable to enhance the rate and extent of drug dissolution over $60 \mathrm{~min}$ in comparison to pure drug powder, it did, however, demonstrate a sustained drug release pattern (Fig. 6). Despite this suboptimal performance shown during in vitro studies, Na-CMC solid SNEDDS enhanced oral bioavailability of flurbiprofen approximately 11-fold above pure drug powder and demonstrated a similar bioavailability enhancement to solid SNEDDS solidified by Aerosil $^{\circledR} 200$ and magnesium stearate (Fig. 3). Significantly, the Na-CMC solid SNEDDS provided a lower maximum plasma concentration $\left(C_{\max }\right)$ in comparison to solid SNEDDS solidified with other carriers, and increased drug half-life $\left(t_{1 / 2}\right)$ 8 -fold in contrast to pure drug powder. The modulation of these parameters clearly indicate that $\mathrm{Na}-\mathrm{CMC}$ is capable first

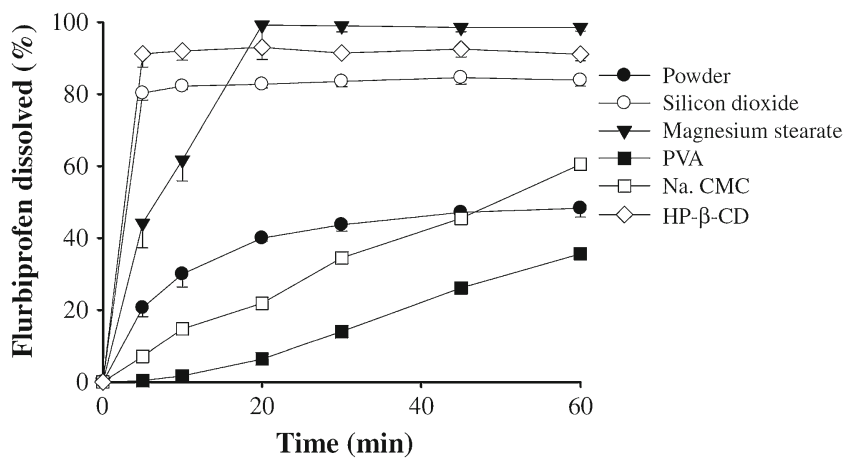

Fig. 6. In vitro dissolution profiles of flurbiprofen from solid selfnanoemulsifying drug delivery systems solidified using various solid carrier materials in $900 \mathrm{~mL}$ water at $36.5^{\circ} \mathrm{C}$. Reprinted with permission from Kang et al. (28) and foremost of producing an effective solid SNEDDS that offers bioavailability enhancement, whilst also reducing maximum plasma drug concentrations with the potential to minimize dose-related drug toxicities and prolong drug circulation times, thus providing sustained release properties and extending therapeutic efficacy. Taken together, natural cellulose-based polymers such as HPMC or Na-CMC are effective and safe solid carriers that may confer the significant advantage of controlled drug release to LBDDS.

Alternatively, synthetic poloxamers have recently been utilized as simultaneous emulsifying and solidifying agents for self-emulsifying formulations by Shah and Serajuddin (36) and Tran et al. (37). Significantly, these polymeric excipients have also previously been used as precipitation inhibitors or supersaturation promoters for LBDDS, further confirming their substantial utility as components of solid-state LBDDS (11). Poloxamer 188 was used to solidify SEDDS by mixing excipients at $75^{\circ} \mathrm{C}$ and allowing the molten mixtures to solidify at room temperature (36). Accordingly, the use of poloxamer 188 as concurrent emulsifier and solidifier allows for maximum lipid and drug loading levels to be achieved in solid SEDDS by avoiding the use of a liquid surfactant and solid carrier material. When redispersed in aqueous media, solid SEDDS composed of poloxamer 188 and liquid-state lipid excipients at a $1: 1 \mathrm{w} / \mathrm{w}$ ratio formed an effective emulsion with droplet size in the range of $200-600 \mathrm{~nm}$. Providing further insight into these types of systems, Tran et al. developed solid SEDDS composed of surfactant, fatty acids and poloxamer 407 via a similar melting method for the poorly water-soluble drug isradipine (37). Of interest, these solid SEDDS were prepared as controlled release tablets via thorough mixing with HPMC and direct compression, in order to circumvent the short half-life of isradipine. Solid SEDDS prepared using poloxamer 407 demonstrated an 
increased rate and extent of drug dissolution in comparison to various other investigated solidifying excipients (i.e. polyethylene glycol 6000 , PVP K30 ${ }^{\circledR}$, and Gelucire 50/13 ${ }^{\circledR}$ ), attributed to increased drug solubility and wettability by inclusion of poloxamer 407. The final controlled release tablets were administered to healthy human volunteers, and AUC and $C_{\max }$ were significantly increased in comparison to the commercial formulation $\left(\right.$ Dynacirc $\left.^{\circledR}\right)$. In this instance, two polymeric excipients were included in the final formulation to provide optimal biopharmaceutical performance. The enhanced dissolution and bioavailability of isradipine in solid SEDDS could be attributed mainly to poloxamer 407, whereas the observed controlled release properties were attained by the inclusion of HPMC.

Importantly, despite Shah and Serajuddin (36) suggesting that poloxamer use allows for increased lipid loading, it should be kept in mind that SLH microparticles and various other solid-state LBDDS may be solidified at a lipid:carrier ratio of $2: 1$, thereby allowing for up to $67 \% w / w$ lipid loading to be achieved.

\section{NOVEL MATERIALS WITH POTENTIAL AS SOLID CARRIERS FOR LIPID-BASED DRUG DELIVERY SYSTEMS}

Whilst solid carriers have traditionally been selected based on their ability to solidify LBDDS and preserve the biopharmaceutical performance of original LBDDS, the studies highlighted in the previous sections demonstrate the vastly untapped potential to enhance in vivo performance or provide further benefits to LBDDS by careful and wellconsidered selection of a specific solid carrier material with optimal physicochemical properties. The use of mesoporous and/or nanosized materials for drug delivery has gained significant momentum in recent years, and thus, we might propose that such materials can also be repurposed for solidifying LBDDS (38-40). When selecting novel materials for LBDDS solidification, consideration must be given to the physicochemical properties of each material, in addition to the anticipated manner in which the material will interact with both lipid excipients and drug molecules (Table II).

The various novel materials discussed in this section were selected on the basis of their interesting/relevant physicochemical properties and proven ability to improve/ modify in vivo delivery of various small molecule drugs (Table III). The following sections will therefore highlight the ability of these materials to be used as drug delivery systems for poorly water-soluble drugs, and will also provide insight into the potential benefits these materials might confer to LBDDS as a result of their specific characteristics.

\section{Inorganic Mesoporous Materials}

Given the interest in mesoporous silica materials for drug delivery applications, various other inorganic mesoporous materials have been developed. These materials generally possess many of the same advantages as silica (i.e. large specific surface area and high pore volume), and examples include mesoporous aluminum oxide, titanium dioxide, carbon, and hydroxycarbonate apatite (38). Of these, mesoporous carbon is of particular interest here.

\section{Mesoporous Carbon}

Mesoporous carbon is a relatively new inorganic material that is fast attracting attention for drug delivery purposes. Mesoporous carbon is typically synthesized via a "hard-template" method, whereby a carbon source such as sucrose is adsorbed to the surface of a mesoporous silica template and subsequently carbonized at high temperatures (38). Accordingly, mesoporous carbon possesses many of the same advantages as mesoporous silica. However, potential improvements over mesoporous silica include (i) higher specific surface area in the order of $1000-2000 \mathrm{~m}^{2} \mathrm{~g}^{-1}$, (ii) larger pore volumes and increased drug loading capacity, (iii) high thermal and mechanical stability, and (iv) low toxicity and proposed excellent biocompatibility $(54,68,69)$. Additionally, mesoporous carbon materials can be tuned for shape, particle size and porosity by virtue of altering the silica template used during synthesis (41).

Over the past few years, mesoporous carbon has been demonstrated as an effective oral delivery system for various poorly water-soluble drugs (50-53). Whereas silica-based materials are hydrophilic (unless modified) and typically contain a high concentration of surface hydroxyl groups, carbon-based materials are inert and hydrophobic due to the absence of any specific surface functional groups. As a result, drug molecules are suggested to interact with the surface of mesoporous carbon by reversible physical adsorptive forces (i.e. van der Waals interactions). This weak interaction generally allows for fast desorption of drug molecules into aqueous media; however, sustained drug release may be achieved due to the very small size of the mesopores and slowed transport of drug molecules through pore channels $(41,54)$. Despite the proven efficacy of this material for enhancing dissolution and bioavailability, its poor wettability can dramatically affect its ability to maximize biopharmaceutical performance of drugs. To overcome this issue, the surface characteristics of mesoporous carbon may be modified to increase hydrophilicity, as demonstrated by Shen et al. (51) and Zhang et al. (53) who prepared oxidized and carboxylated mesoporous carbon materials, respectively.

For the solidification of LBDDS, mesoporous carbon may offer the potential to control lipid/drug release in a similar manner to that seen when polymer-based materials are used as solid carriers. This characteristic might be attributable to the small mesopores and hydrophobic properties of the carbon material, thereby slowing the rate of lipid/ drug release. In addition, the mesopores are often in the size range of 3-6 nm, and this may inhibit the ability of lipase enzymes to enter mesoporous carbon particles and access encapsulated lipid. The approximate diameter of lipase is known to be $4.5 \mathrm{~nm}$, and previous studies have demonstrated that small pore sizes of mesoporous silica $(5-6 \mathrm{~nm})$ reduce lipase activity by restricting the ability of the lipase lid domain to open and expose the enzyme active site for substrates $(26,70,71)$. In such a situation, lipid excipients would need to diffuse from the mesoporous carbon to be digested. As mentioned, this process may be further slowed by the increased affinity of lipid excipients for the hydrophobic carbon surface. Optimization of mesopore size is thus important to achieve ideal in vivo results, and the fabrication of mesoporous carbon materials with larger pore sizes (i.e. 9, 20-25, and 40-60 nm) has already been demonstrated in the 


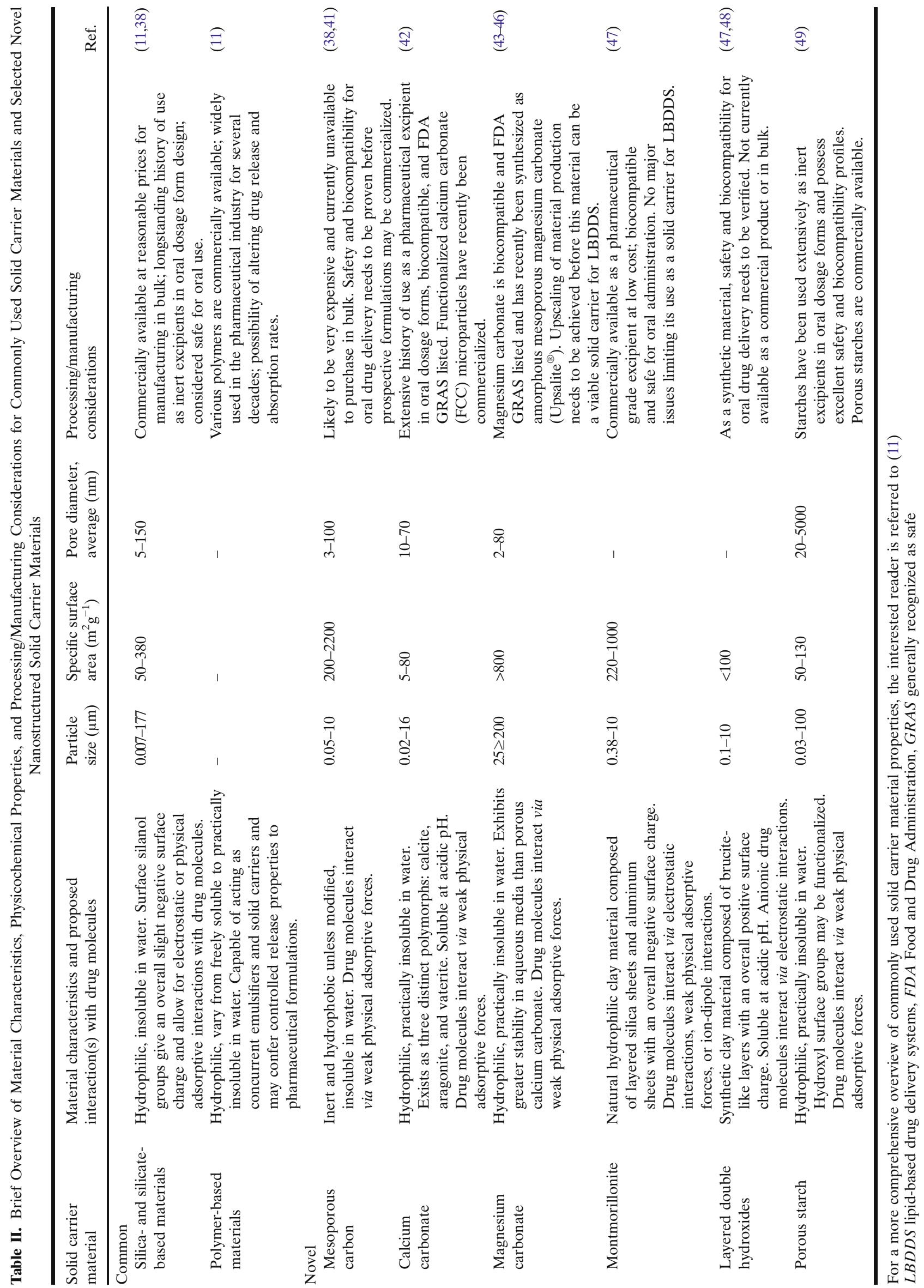


Table III. Examples of Studies Examining the In Vitro and/or In Vivo Performance of Poorly Water-Soluble Drugs from Various Oral Nanostructured Drug Delivery Systems Prepared Using Novel Solid Carrier Materials

\begin{tabular}{|c|c|c|c|c|c|c|}
\hline Solid carrier & Compound & Other included excipient(s) & $\begin{array}{l}\text { Drug loading } \\
(\% w / w)\end{array}$ & In vitro & In vivo & Ref. \\
\hline \multirow[t]{7}{*}{ Mesoporous carbon } & Fenofibrate & - & $25.7-67.9$ & $\mathrm{x}$ & $\mathrm{x}$ & $(50)$ \\
\hline & Indomethacin & - & 43.4 & $\mathrm{x}$ & & (51) \\
\hline & Simvastatin & - & $22.6-40.1$ & $\mathrm{x}$ & $\mathrm{x}$ & $(52)$ \\
\hline & Carvedilol & - & $30.1-41.6$ & $\mathrm{x}$ & $\mathrm{x}$ & (53) \\
\hline & Celecoxib & - & $26.4-59.9$ & $\mathrm{x}$ & $\mathrm{x}$ & (54) \\
\hline & Lovastatin & - & $25.6-36.3$ & $\mathrm{x}$ & & (41) \\
\hline & Nimodipine & DOTAP, DPPC, cholesterol & $27.3-30.1$ & $\mathrm{x}$ & $\mathrm{x}$ & $(55)$ \\
\hline \multirow[t]{2}{*}{ Calcium carbonate } & Celecoxib & - & $8-25$ & $\mathrm{x}$ & & (56) \\
\hline & $\begin{array}{l}\text { Ibuprofen, nifedipine, } \\
\text { losartan and } \\
\text { metronidazole }\end{array}$ & - & $25-50$ & $\mathrm{x}$ & & (57) \\
\hline \multirow[t]{2}{*}{ Magnesium carbonate } & Ibuprofen & - & 24 & $\mathrm{x}$ & & $(45)$ \\
\hline & Ibuprofen & - & $29.2-30.6$ & $\mathrm{x}$ & & $(46)$ \\
\hline \multirow[t]{4}{*}{ Montmorillonite } & Timolol & - & 17 & $\mathrm{x}$ & & (58) \\
\hline & Aripiprazole & Polyvinylacetal diethylaminoacetate & $16.8-27.3$ & $\mathrm{x}$ & $\mathrm{x}$ & (59) \\
\hline & Glutathione & Polyvinylacetal diethylaminoacetate & $35.9-61.9$ & & $\mathrm{x}$ & $(60)$ \\
\hline & Fenofibrate & Polyvinylpyrrolidone & $20-50$ & $\mathrm{x}$ & & (61) \\
\hline \multirow{3}{*}{$\begin{array}{l}\text { Layered double } \\
\text { hydroxides }\end{array}$} & Bezafibrate and clofibric acid & - & $45-54$ & $\mathrm{x}$ & & $(62)$ \\
\hline & Naproxen and flurbiprofen & - & $21-52$ & $\mathrm{x}$ & & (63) \\
\hline & Ursodeoxycholic acid & Eudragit $\mathrm{S} 100^{\circledR}$ & $27.3-60.9$ & $\mathrm{x}$ & & (64) \\
\hline \multirow[t]{3}{*}{ Porous starch } & Lovastatin & - & $6.3-16.7$ & $\mathrm{x}$ & $\mathrm{x}$ & $(65)$ \\
\hline & Carbamazepine & - & 50 & $\mathrm{x}$ & $\mathrm{x}$ & (66) \\
\hline & Probucol & $\begin{array}{l}\text { Medium-chain triglycerides, } \\
\text { Cremophor EL }{ }^{\circledR} \text {, and } \\
\text { Transcutol HP }{ }^{\circledR}\end{array}$ & 6.3 & $\mathrm{x}$ & $\mathrm{x}$ & $(67)$ \\
\hline
\end{tabular}

DOTAP 1,2-dioleoyl-3-trimethylammonium propane, DPPC 1,2-dipalmitoyl-sn-glycero-3-phosphocholine

literature (52,72-74). As well as this potential to modulate lipid/drug release, it could also be proposed that mesoporous carbon might allow for increased drug and lipid loading levels above those more commonly used solid carrier materials. The very large surface area of mesoporous carbon can be exploited for enhancing drug and lipid loading, thereby overcoming one of the major limitations of LBDDS.

Whilst mesoporous carbon has not yet been investigated for solidifying LBDDS, Zhang et al. recently engineered a novel mesoporous carbon/lipid bilayer nanocomposite (MCLN) with core-shell structure for oral drug delivery (55). These delivery systems consist of a mesoporous carbon nanoparticle (particle size $173 \pm 16 \mathrm{~nm}$, specific surface area $1494 \pm 25 \mathrm{~m}^{2} \mathrm{~g}^{-1}$, and pore size $3.0 \pm 0.2 \mathrm{~nm}$ ) loaded with the poorly water-soluble drug nimodipine, which is enveloped by lipid bilayers. The mesoporous carbon core was designed to control and optimize drug loading and release, whilst the lipid bilayers confer better biocompatibility and may reduce or eliminate any initial burst release of drug molecules. Nimodipine was loaded into MCLNs at a level of 27.3 \pm $0.6 \% w / w$, and a final particle size of $196 \pm 35 \mathrm{~nm}$ was obtained. Aqueous solubility of nimodipine was enhanced approximately 6-fold, and MCLNs were capable of sustaining drug release in comparison with the commercial formulation $\left(\right.$ Nimotop $\left.^{\circledR}\right)$, with approximately $100 \%$ drug release achieved after $18 \mathrm{~h}$. Further, the initial burst release seen with mesoporous carbon particles was completely annulled by the addition of lipid bilayers. MCLNs enhanced oral bioavailability 2.1 -fold above Nimotop ${ }^{\circledR}$, and increased $T_{\max }$ (4.3 versus
$1.4 \mathrm{~h})$ and lowered $C_{\max }(130$ versus $274 \mathrm{ng} / \mathrm{mL})$ of the MCLNs indicates sustained drug release was also achieved in vivo. A similar approach to that used in this study could be investigated for solidifying LBDDS using mesoporous carbon as solid carrier, whereby drugs can be loaded directly into mesoporous carbon, and then drug-loaded LBDDS can be solidified with this material. This approach offers the potential to substantially enhance drug loading levels in the final formulation, whilst possibly offering an interesting dual-step drug release profile, i.e. fast release of drug encapsulated in lipid followed by slower release of drug directly adsorbed to the mesoporous carbon surface.

\section{Porous Carbonate Salts}

Significant interest has focused on the use of biocompatible porous carbonate salts for various drug delivery applications. Much of this research is centered around the characteristic dissolution of these materials in acidic environments, with an emphasis on use as parenteral delivery vehicles in cancer treatment due to $\mathrm{pH}$-dependent release of cargo within acidic cancer cells. For oral drug delivery, this $\mathrm{pH}$ sensitivity also needs to be given significant consideration. Dose dumping and precipitation of poorly watersoluble drugs prior to reaching the small intestines is a substantial risk, particularly for acidic drugs that exhibit low solubility at low $\mathrm{pH}$. Additionally, carbonate salts are commonly used as antacids, and this ability to neutralize stomach acid could further impact delivery of basic drugs by 
reducing their solubility within the stomach. Clearly, there is much to be considered when proposing these materials for oral drug delivery. However, careful consideration and engineering of oral solid-state LBDDS with these materials could minimize the potential disadvantages, or conversely, exploit this $\mathrm{pH}$ sensitivity to advantage.

\section{Calcium Carbonate}

Calcium carbonate has an extensive history of use as a pharmaceutical excipient in dosage forms, mainly as a diluent, bulking agent and dissolution aid in dispersible tablets (21). For medical purposes, it has also been utilized as an antacid, calcium supplement, and phosphate binder (75). Calcium carbonate exists as three distinct polymorphs: calcite (rhombohedral crystals), aragonite (needle-like crystals), and vaterite (spherical porous structures composed of aggregated nanoparticles) (42). For drug delivery, interest has mainly focused on the use of porous vaterite particles. Vaterite does not occur naturally, but may be formed from amorphous calcium carbonate (i.e. reaction between $\mathrm{Ca}^{2+}$ and $\mathrm{CO}^{2-}$ salts) and presents an increased specific surface area (typically in the range of $5-50 \mathrm{~m}^{2} \mathrm{~g}^{-1}$ ) compared with the other polymorphs (76). This characteristic, in addition to its ability to break down under mild conditions in vivo, has made it a potential candidate for oral drug delivery (77). Various other advantages include (i) low cost and ease of preparation, (ii) potential for $\mathrm{pH}$-dependent drug release, and (iii) ideal biocompatibility and biodegradability $(78,79)$.

In recent years, calcium carbonate has been used as both nanoparticles and porous vaterite microparticles for drug delivery. During synthesis, amorphous nanosized particles aggregate in solution to form porous vaterite microparticles; however, the use of various additives (e.g. ethylene glycol) can halt the aggregation process and allow individual calcium carbonate nanoparticles to be obtained (80). Drug molecules are expected to interact with calcium carbonate via simple physical adsorptive forces, and accordingly, drug release from calcium carbonate is proposed to occur via a combination of drug desorption and calcium carbonate dissolution (77). When applied to deliver anticancer compounds via the intravenous route, drug release is triggered by the acidic extracellular environment in solid tumor tissues $(\mathrm{pH} \mathrm{6)}$ or lysosomes within cancer cells ( $\mathrm{pH} 4.5$ ), as opposed to minimal drug release occurring under normal physiological conditions (81). For oral delivery of poorly water-soluble drugs, few studies have been published. A recent study by Forsgren et al. investigated the use of porous vaterite microparticles to encapsulate celecoxib, with drug dissolution enhanced up to 6-fold in comparison to pure drug, and attributed to poreinduced drug amorphization (56). Of major interest, this study highlights the most significant limitation of calcium carbonate microparticles, that is, instability in the presence of water resulting in transformation from vaterite to the nonporous calcite or aragonite polymorphs (Fig. 7). Following storage at $100 \%$ relative humidity for 7 days, X-ray powder diffraction (XRPD) analysis and SEM images revealed crystalline aragonite to be the predominant polymorph present. Further, XRPD patterns suggested an increased quantity of crystalline celecoxib, as a result of non-porous aragonite expelling amorphous celecoxib from vaterite pores
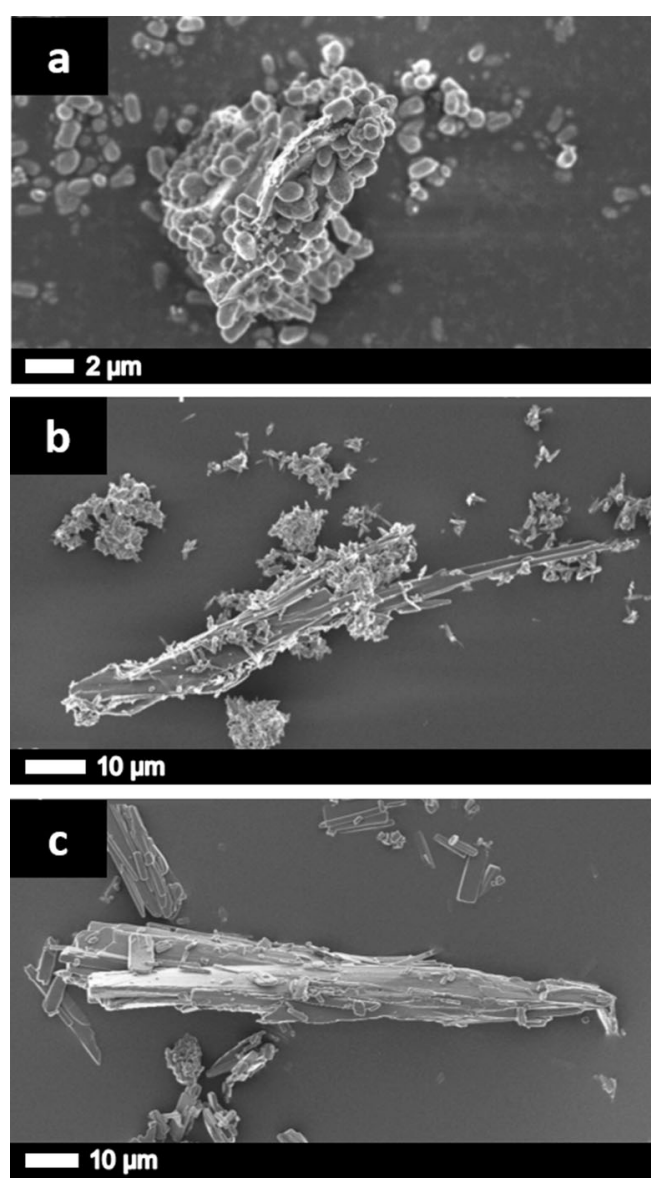

Fig. 7. Scanning electron microscope images of a freshly synthesized calcium carbonate microparticles loaded with $25 \% \mathrm{w} / \mathrm{w}$ celecoxib, b calcium carbonate microparticles with $25 \% \quad w / w$ celecoxib after storage at $100 \%$ relative humidity for 7 days, and $\mathbf{c}$ pure crystalline celecoxib. Reprinted with permission from Forsgren et al. (56)

and causing subsequent drug recrystallization. This issue poses serious concerns for oral drug delivery and limits further evaluation in vivo. Phase transformation of calcium carbonate within the aqueous GI environment and $\mathrm{pH}$-induced dissolution in the stomach poses the risk of immediate poorly water-soluble drug expulsion and precipitation within the GIT. Thus, these issues must be resolved for this carrier to progress as a genuine option for improved oral drug delivery.

The use of either calcium carbonate nanoparticles or porous vaterite microparticles could be suggested for solidification of LBDDS. Similar to the use of Aerosil ${ }^{\circledR}$ silica nanoparticles for engineering SLH microparticles, calcium carbonate nanoparticles could be used to form solid-state LBDDS via aggregation through a drying process such as spray-drying or freeze-drying. The hybridization of calcium carbonate with lipid excipients may provide some interesting performance characteristics, such as protection of calcium carbonate from $\mathrm{pH}$-induced dissolution within the stomach. A further consideration, rapid dissolution of the solid carrier within the GIT would result in fast LBDDS release, and accordingly, fast drug absorption may be attained, a potential advantage for some drugs where rapid onset of action is desirable. Recently, functionalized calcium carbonate (FCC) microparticles have been commercialized as a pharmaceutical excipient for delivering poorly water-soluble drugs $(57,82,83)$. 
FCC is composed of crystalline calcium carbonate and, therefore, does not carry the risk of phase transformation in aqueous media. Such an excipient could prove highly useful for solidifying LBDDS, particularly given the excellent biocompatibility of calcium carbonate.

\section{Magnesium Carbonate}

Recently, mesoporous magnesium carbonate has emerged as a new and improved alternative to porous calcium carbonate. Synthesis of anhydrous magnesium carbonate has challenged chemists since the early 1900s; however, amorphous magnesium carbonate with large specific surface area and mesoporous/microporous nature has been successfully synthesized and commercialized as Upsalite $^{\circledR}$ (Fig. 8) (4345). Unlike porous calcium carbonate which is unstable in aqueous media and poses challenges for oral drug delivery, Upsalite $^{\circledR}$ appears to be highly stable in aqueous environments. Further, specific surface areas of up to $800 \mathrm{~m}^{2} \mathrm{~g}^{-1}$ have been demonstrated for Upsalite ${ }^{\circledR}$, significantly higher than that achieved for porous calcium carbonate. Upsalite ${ }^{\circledR}$ not only offers a comparable surface area to mesoporous silica materials, but also offers other advantages including lower manufacturing costs and increased affordability (e.g. SigmaAldrich currently sells MCM-41 mesoporous silica for approximately $\$ 600$ US per $25 \mathrm{~g}$ ) (84).

Only two studies have been published on the use of Upsalite $^{\circledR}$ for drug delivery thus far $(45,46)$. In the first study, ibuprofen was loaded into Upsalite ${ }^{\circledR}$ (specific surface area $349 \pm 1 \mathrm{~m}^{2} \mathrm{~g}^{-1}$, pore size range 5-10 nm) via ethanol, with a drug loading level of $24 \% w / w$ achieved (45). Differential scanning calorimetry (DSC) and XRPD studies confirmed ibuprofen to be encapsulated entirely in the molecularly dispersed form, thereby verifying the potential of mesoporous magnesium carbonate to stabilize amorphous drug molecules. To gain an understanding of how drug molecules interact with Upsalite $^{\circledR}$, Fourier transform infrared (FTIR) spectra of pure drug, Upsalite ${ }^{\circledR}$, and drug-loaded Upsalite ${ }^{\circledR}$ samples were analyzed. FTIR spectra indicated that ibuprofen molecules were physically adsorbed to the surface of Upsalite ${ }^{\circledR}$. As a result, fast dissolution of amorphous ibuprofen molecules could be anticipated, and in vitro dissolution studies revealed diffusion-controlled drug release kinetics and an enhanced drug release rate from Upsalite ${ }^{\circledR}$ in comparison to pure drug (3-fold increase within the first $5 \mathrm{~min}$ ). In the follow-on study, Upsalite ${ }^{\circledR}$ particle size was controlled to allow the impact of particle size on drug release/dissolution to be evaluated (46).
Upsalite ${ }^{\circledR}$-large (particle size $>200 \mu \mathrm{m}$ ), Upsalite ${ }^{\circledR}$-medium (particle size 75-100 $\mu \mathrm{m}$ ), and Upsalite ${ }^{\circledR}$-small (particle size 25-50 $\mu \mathrm{m}$ ) were prepared via grinding and sieving, and each material was loaded with ibuprofen via ethanol, with drug loading levels of $30.1,29.2$, and $30.6 \% \mathrm{w} / \mathrm{w}$ achieved, respectively. As expected, all $3 \mathrm{Upsalite}^{\circledR}$ samples increased the drug release rate in comparison to pure drug; however, particle size had a significant impact on the initial drug release rate from Upsalite ${ }^{\circledR}$. During the first $10 \mathrm{~min}$, approximately 36,70 , and $86 \%$ ibuprofen was released from Upsalite ${ }^{\circledR}$-large, Upsalite ${ }^{\circledR}$-medium, and Upsalite ${ }^{\circledR}$-small, respectively, thereby demonstrating the ability of Upsalite ${ }^{\circledR}$ to alter drug release profiles by regulation of material particle size. After the initial rapid release phase whereby all 3 samples released 70-88\% ibuprofen after 14-52 min, it took a total of $24 \mathrm{~h}$ for maximum drug release to be achieved (87$98 \%$ ) from Upsalite ${ }^{\circledR}$. The authors proposed the latter slow release phase from all 3 samples to be attributed to interactions between carboxylic groups of ibuprofen and hydroxyl groups remaining on the surface of Upsalite ${ }^{\circledR}$ after synthesis. Notably, dissolution experiments in both studies were only conducted in pH 6.8 phosphate buffer, and thus further studies into the performance of this carrier under both simulated gastric and intestinal conditions are required to gain a better insight into how this delivery system would behave in vivo.

Given its similarities with calcium carbonate, we might also suggest that mesoporous magnesium carbonate possesses various similar characteristics that make it an interesting solid carrier material to investigate for solidifying LBDDS. Additionally, the very large specific surface area offered by this material could increase drug and lipid loading capabilities, similar to that previously suggested for mesoporous carbon.

\section{Clay-Based Materials}

Various clay-based materials have long been used as excipients in pharmaceutical dosage forms, owing to their ability to act as emulsifying agents, viscosity enhancers, and most significantly here, adsorbent materials (21). Therapeutically, clays have also been used as antidiarrheals, antacids, and gastrointestinal protectors/detoxifiers, thereby demonstrating their usefulness and versatility as both excipients and active pharmaceutical substances (85). These biocompatible and non-toxic materials have more recently attracted substantial attention for modifying drug release, owing to early observations that co-administration of some drugs with clays
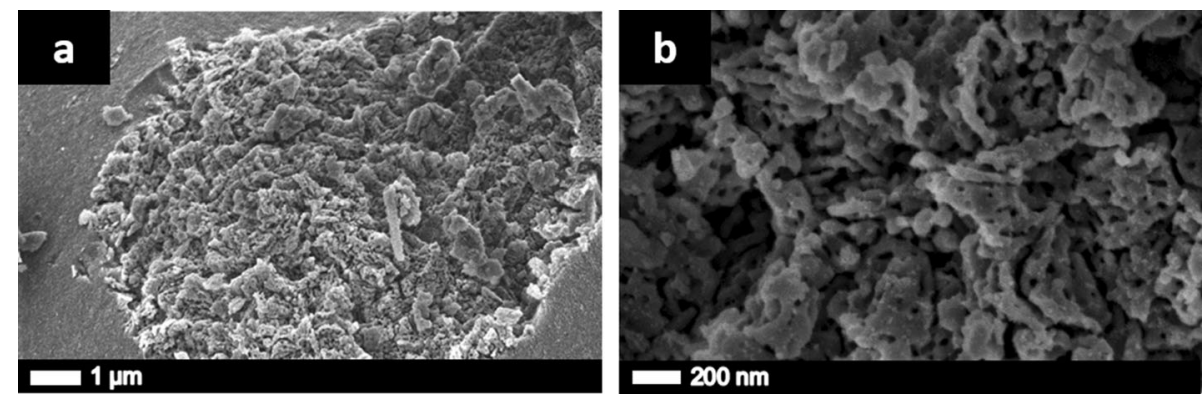

Fig. 8. Scanning electron microscope images of mesoporous magnesium carbonate (Upsalite ${ }^{\circledR}$ ) under a low magnification and $\mathbf{b}$ high magnification. Reprinted with permission from Forsgren et al. (43) 
resulted in reduced oral drug absorption. Whilst such a phenomenon is typically considered unfavorable, the realization occurred that such interactions could be exploited to produce superior biopharmaceutical performances (86). Montmorillonite, a natural clay material, and layered double hydroxides (LDH), a synthetic clay material, have been the most commonly investigated clay-based materials for actively modulating drug release.

\section{Montmorillonite}

Montmorillonite is a natural clay-based material purified from bentonite clay. Structurally, montmorillonite is composed of tetrahedral silica sheets layered between aluminum octahedral sheets and, thus, can be considered a type of aluminosilicate. The sheets of montmorillonite carry an overall negative surface charge, due to the substitution of some $\mathrm{Al}^{3+}$ with $\mathrm{Mg}^{2+}$. As a result, interlayer cations such as $\mathrm{Na}^{+}$are adsorbed within the layers of montmorillonite to neutralize charge (58). Given that the interlayer cations are not structural, these can easily be replaced by other positively charged atoms or molecules (e.g. basic drugs). This capability underpins the use of montmorillonite for modifying drug release.

As might be expected, the majority of published studies have investigated the loading and release of cationic drug molecules from montmorillonite clay (58-60). Although much less common, anionic drug molecules may also be adsorbed onto montmorillonite, as the edges of the clay sheets carry a slight positive charge due to lattice discontinuities (87). To fabricate montmorillonite-drug complexes, montmorillonite and crystalline drug are dispersed in aqueous media under controlled $\mathrm{pH}$ and allowed to equilibrate, prior to recovering of solid materials and drying. Similar to other high surface area materials, poorly water-soluble drugs can also be adsorbed onto montmorillonite via organic solvents, thereby producing weaker physical interactions between clay and drug molecules that are useful for enhancing dissolution and bioavailability. For cationic drugs, intercalation within montmorillonite via cation exchange results in strong electrostatic interactions that then confer the characteristic-controlled release properties. For anionic or neutral drugs, significantly weaker physical adsorption or ion-dipole interactions are suggested, and consequently, drug release is typically faster (47).

Enhanced dissolution and oral bioavailability have been demonstrated for various poorly water-soluble drugs loaded into montmorillonite (58-60). However, perhaps the most significant limitation of montmorillonite is its propensity to cause incomplete drug release, as demonstrated by Joshi et al. (58). Timolol maleate as model poorly water-soluble drug was loaded into montmorillonite from aqueous media with controlled $\mathrm{pH}$. In vitro release studies were undertaken in SGF ( $\mathrm{pH}$ 1.2) and SIF ( $\mathrm{pH}$ 7.4) and sustained drug release profiles were obtained in both media over a $9 \mathrm{~h}$ period, attributed to the ion-exchange process between intercalated drug molecules and alkali metal cations present in the release media. Crucially, $100 \%$ drug release was not achieved (i.e. approximately $40-50 \%$ drug release attained at the end of the studies), despite release profiles appearing to reach equilibrium during the time course of the experiment. This phenomenon can be attributed to the ion-exchange process, which is an equilibrium reaction and thus interlayer cations cannot be exchanged completely. Further, large and bulky cations (i.e. drug molecules) cannot be as easily exchanged with simple cations (i.e. alkali metal cations) (88). Therefore, relatively small $\mathrm{K}^{+}$and $\mathrm{Na}^{+}$ions present in the release media are unable to completely exchange with intercalated timolol, resulting in incomplete drug release. To overcome this significant limitation, several researchers have included additional excipients (i.e. larger polymeric materials) in montmorillonite delivery systems to allow maximum drug release and bioavailability to be obtained. For example, Oh et al. included the cationic polymer polyvinylacetal diethylaminoacetate in montmorillonite-aripiprazole complexes, which acted to enlarge the interlayer spaces of montmorillonite and also facilitated drug release by exchanging with the smaller aripiprazole molecules in vivo (59).

Significantly, montmorillonite and other clay-based materials have a longstanding history of use as particulate emulsifiers (i.e. Pickering emulsion stabilizers), and this capability presents an excellent opportunity to extrapolate their use in drug delivery to the solidification of LBDDS $(89,90)$. Similar to SLH microparticles where silica nanoparticles stabilize oil-in-water emulsions prior to drying, montmorillonite can also be utilized in a similar manner to reduce the quantity of surfactants required to produce stable emulsions. Given the potential safety issues associated with long-term use of surfactant-containing formulations (i.e. GI irritation), the use of a solid carrier with emulsifying capabilities is a significant advantage. Of interest, Dong et al. recently used montmorillonite as a "matrix" material to stabilize nanosuspensions of the poorly water-soluble drug fenofibrate, whereby freshly synthesized drug nanoparticles were spray-dried with montmorillonite and PVP (as stabilizer) to form aggregated porous microparticles (61). With the addition of lipid excipients, similar structures might be expected. To optimize delivery systems, preloading of montmorillonite with drug could offer two distinct advantages, (i) increased drug-loading levels in the final solid-state LBDDS, and (ii) modulated drug release profiles owing to drug being encapsulated within montmorillonite via electrostatic interactions, as well as dissolved in LBDDS. Further, montmorillonite is readily available as a pharmaceutical grade excipient (e.g. Veegum ${ }^{\circledR} \mathrm{HS}$ ), and so the regulatory challenges that may exist for other novel materials are not a major issue for montmorillonite.

\section{Layered-Double Hydroxides}

LDHs are a class of synthetic clay-based materials, which possess a similar structure to brucite $\left(\mathrm{Mg}(\mathrm{OH})_{2}\right)$ and have attracted significant attention for drug delivery in recent years. Whilst also possessing a layered sheet structure similar to montmorillonite, LDH materials carry an overall positive surface charge with interlayer anions (e.g. $\mathrm{CO}_{3}{ }^{2-}, \mathrm{NO}_{3}{ }^{-}$) adsorbed within to neutralize charge (91).

As expected, LDHs are capable of modifying drug release via electrostatic interactions between the $\mathrm{LDH}$ material and intercalated anionic drug molecules (92,93). However, drug release from LDHs occurs via two proposed mechanisms, (i) ion exchange between intercalated anionic drug molecules and anions present in the GI fluids, and (ii) 
dissolution of the LDH material in acidic environments. Significantly, dissolution of the solid carrier under acidic conditions has profound implications for use in oral drug delivery systems. Whilst several researchers have simply proposed the use of enteric coatings to overcome this issue, Parello, Rojas, and Giacomelli studied the dissolution kinetics of LDHs at various $\mathrm{pH}$ levels to better understand the process (94). LDH dissolution was found to depend on $\mathrm{pH}$, interaction with intercalated drug, and exposed LDH surface area. In highly acidic media (akin to gastric fluids), dissolution of LDHs was rapid and complete. Although this characteristic can be exploited for targeted drug delivery following parenteral administration (i.e. similar to that demonstrated with calcium carbonate), it poses significant challenges for progressing oral drug delivery systems, particularly when considering anionic drug molecules with inherent low solubility in acidic media. The other major limitation of LDHs is the same as for montmorillonite; incomplete drug release. A plethora of studies have been published demonstrating the loading and release of anionic drug molecules from LDHs; however, very few in vivo studies have been reported, presumably due to the aforementioned limitations. As such, further research is required to better understand the ability of this material to control and optimize oral drug absorption in vivo.

Given the numerous similarities with montmorillonite, LDH materials can be considered an almost equivalent solid carrier material for potential solidification of LBDDS. Ultimately, these materials are more useful for encapsulation and delivery of anionic drug molecules, opposite to that demonstrated for montmorillonite. Likewise to montmorillonite, $\mathrm{LDH}$ particles are also capable of stabilizing Pickering emulsions and, thus, may also be used to solidify LBDDS in a similar manner to SLH microparticles (95-97). Of interest, Rahman et al. utilized LDHs as a platform for adsorbing lipase enzymes from Candida rugosa to act as a biocatalyst for synthesizing esters $(98,99)$. The large surface area of LDHs $\left(53 \mathrm{~m}^{2} \mathrm{~g}^{-1}\right)$ allowed $58-71 \% \mathrm{w} / \mathrm{w}$ lipase loading, and immobilization of lipase onto LDHs was found to optimize the reaction kinetics in comparison to native lipase (99). Whilst this interaction was exploited for a completely different purpose than drug delivery, there may be important implications for oral drug delivery in terms of $\mathrm{LDH}$ materials interacting with lipase enzymes. Joyce et al. previously proposed lipase enzymes to interact with porous silica adsorbents during lipid digestion, and we might also consider the potential of LDHs affecting lipase enzyme action in vivo (26). Such an interaction might increase or decrease lipid digestion, with implications for poorly water-soluble drug solubilization and absorption.

\section{Carbohydrate-Based Materials}

Whilst various polysaccharide-based materials have been used extensively as solid carriers for LBDDS, other carbohydrate-based materials have not been investigated to the same level. Given their excellent biocompatibility and regular presence in our everyday diets, these materials could be considered an optimal choice of solid carrier material for
LBDDS. Specifically, porous starch offers various advantages as a solid carrier material.

\section{Porous Starch}

Versatile starch derivatives have enjoyed a long and extensive history of use in oral dosage forms, owing to their non-toxic and non-irritant, biocompatible nature. Owing to its popularity as an excipient in oral dosage forms, starch has previously been used as a solid carrier for LBDDS. Ge et al. and Abdelbary et al. used starch derivatives to effectively prepare redispersible dry emulsions and solid SNEDDS, respectively $(100,101)$. Given that native starch has a low specific surface area and poor drug adsorption capabilities, various researchers have synthesized porous starch microparticles. Such porous materials are capable of enhancing poorly watersoluble drug dissolution and bioavailability, owing to their dramatically increased specific surface areas (up to $130 \mathrm{~m}^{2} \mathrm{~g}^{-1}$ ), porous structures and high pore volumes $(65,67)$.

Significantly, porous starch has previously been used to solidify LBDDS in a recent study by Zhang et al. (67). SNEDDS (composed of medium-chain triglycerides, Cremophor $\mathrm{EL}^{\circledR}$, and Transcutol $\mathrm{HP}^{\circledR}$ ) of probucol were loaded into macroporous starch via a spraying method. For comparison, probucol was also loaded directly into the starch from ethanol. In vitro dissolution studies undertaken at $\mathrm{pH} 1.2$ and $\mathrm{pH} 6.8$ illustrated rapid dissolution of probucol, i.e. solid SNEDDS achieved greater than $80 \%$ probucol dissolution within approximately $15 \mathrm{~min}$ irrespective of media type, whereas porous starchprobucol achieved less than 5\% dissolution within 60 min (similar to pure drug). This result is contrary to various other studies that have demonstrated the ability of porous starch to directly enhance poorly water-soluble drug dissolution $(65,66)$. However, the larger pore sizes of the porous starch used by Zhang et al. (i.e. 600-1100 versus $200 \mathrm{~nm}$ in previously described studies) may explain this suboptimal in vitro performance. Indeed, XRPD and DSC analyses indicated the presence of crystalline drug in the porous starchprobucol system, whereas solid SNEDDS encapsulated drug entirely in the molecularly dispersed form. Thus, we might suggest the porous starch pore sizes were too large to induce drug amorphization and corresponding dissolution enhancement. Furthermore, solid SNEDDS provided a 10-fold improvement in bioavailability compared to pure drug, and this is more significant than the porous starch-probucol system which enhanced oral bioavailability 2.7 -fold above pure drug. However, the results indicate that porous starch itself played a significant role in the overall bioavailability improvement demonstrated for solid SNEDDS.

In spite of these advantageous features, consideration must be given to the impact of amylase enzymatic degradation of the solid carrier that will invariably occur in vivo. Similar to LBDDS where we must consider the influence of lipase-mediated digestion on drug absorption processes, digestion of starch will likely impact biopharmaceutical performance. The use of more sophisticated in vitro models that more closely mimic the GI environment in comparison to simple dissolution apparatuses is therefore warranted. In vitro lipolysis models, now commonly used for characterizing LBDDS, may be a suitable solution. Pancreatin extract used to supply lipase enzymes also contains amylase enzymes, and therefore, digestion of starch in addition to any lipid excipients will also occur. However, the dose of pancreatin extract applied to each lipolysis experiment is typically calculated on the basis of replicating 
physiological lipase concentrations, and may need to be adjusted to take into consideration amylase concentrations.

\section{SAFETY ASSESSMENT AND TOXICITY CONCERNS}

The use of novel materials for oral drug delivery is associated with various regulatory challenges, in terms of proving biocompatibility and safety prior to human use. Whilst the oral route generally poses considerably lower risks in comparison to other more invasive routes of administration (e.g. parenteral), emphasis by regulatory agencies on the safety of nanostructured materials has drastically increased in recent times due to the significant advances being made in the field of nanomedicine (102). Similar to fumed silica nanoparticles (i.e. Aerosil ${ }^{\circledR}$ range) which are widely used and verified safe excipients for the manufacture of various pharmaceutical products, the repurposing of known and biocompatible pharmaceutical excipients (e.g. montmorillonite, carbonate salts, or starch) for solidifying LBDDS poses smaller regulatory hurdles when striving for marketing approval. Such materials have been used safely in oral dosage forms as inert excipients for several decades and, therefore, can be considered ideal solid carrier materials for investigation. For those synthetic or highly innovative new materials (e.g. mesoporous carbon or LDHs), a more comprehensive safety assessment will be required to prove the safe (nontoxic) and biocompatible nature of these materials following oral delivery. Whilst the majority of studies into safety and biocompatibility of novel materials for drug delivery focus on parenteral administration, the importance of also verifying oral safety is increasingly being recognized. For mesoporous carbon, several studies have also investigated in vitro and/or in vivo biocompatibility alongside important proof-of-concept oral pharmacokinetic studies (50,55,74,103-105). For example, Niu et al. examined the potential irritant effects of mesoporous carbon on the GIT, by undertaking a gastric mucosa irritation test (50). Rats were orally administered saline (as control) or mesoporous carbon in aqueous suspension at doses of 30,60 , or $150 \mathrm{mg} / \mathrm{kg}$ under a twice daily dosing protocol for 1 week. Animals were sacrificed and stomachs were removed, tissue sections were then examined microscopically for signs of toxicity. No visible differences were observed between the control group and any of the treatment groups, with a complete absence of hyperemia or lesions indicating oral biocompatibility of this material. Alternatively, many studies have focused on investigating biocompatibility of LDHs for parenteral administration; however, few have studied the oral safety of these materials (48).

A further consideration, long-term toxicity and biocompatibility studies should be undertaken to verify the safety of solidstate LBDDS solidified with novel nanostructured material(s), owing to the chronic nature of some medical conditions, thereby requiring long-term pharmacological treatment.

\section{COMMERCIALIZATION PERSPECTIVES}

Despite the interest and significant research advances made in the area of solid-state LBDDS in recent years, no solid-state LBDDS products have been successfully commercialized as yet. Perhaps the most obvious hurdle for solidstate LBDDS to overcome is that which also challenges simple liquid-state LBDDS, low drug solubility in lipid excipients and resultant low drug loading levels. The solubility of a poorly water-soluble drug in lipid excipients dictates the maximum quantity of drug that can be loaded within the LBDDS and final dosage form (e.g. gelatin capsule), and for high-dose drugs or those drugs displaying mediocre solubility in lipid excipients, this can be a significant limitation. By the inclusion of a solid carrier, the drug concentration in the final dosage form can be further diluted. Thus, solid-state LBDDS would seem to be a viable formulation option only for lowdose drugs with appropriate solubility in lipid excipients, thereby limiting the potential commercial success of this formulation strategy. As proposed throughout this review, however, preloading of high surface area nanostructured solid carriers with drug prior to adsorption of LBDDS has the potential to overcome this significant drawback and maximize the utility of solid-state LBDDS. Careful selection of the most appropriate candidate poorly water-soluble drugs for reformulation as solid-state LBDDS might also improve commercialization prospects.

Further, as demonstrated throughout the first half of this review, there is currently conflicting evidence available in the literature as to whether solid-state LBDDS will preserve, increase, or decrease the in vivo biopharmaceutical performance of the original liquid-state LBDDS. This generalized lack of understanding of how solidification impacts on performance makes it challenging to optimize solid-state LBDDS and achieve commercial success. Further research in the field aimed at better understanding how the various formulation variables (e.g. solidification method, solid carrier material and specific lipid excipients) impact the final solidstate LBDDS is required to maximize the chances of solidstate LBDDS products reaching the pharmaceutical marketplace in the near future. In addition, the use of solid carrier materials that are cost-effective, biocompatible, and for which ease of upscale for commercial manufacturing can be achieved are most desirable for achieving commercial success with solid-state LBDDS.

\section{CONCLUSIONS}

Owing to the popularity of LBDDS as a bioavailabilityenhancing formulation strategy for poorly water-soluble drugs in recent years, interest in solid-state LBDDS has exploded as a result of their ability to maintain the advantages of LBDDS whilst enhancing storage stability. Most commonly, solid carrier materials for LBDDS have been chosen based on their ability to encapsulate a large lipid load and produce a free flowing powder suitable for use in capsules or tablets. Herein, we have challenged the reader to consider the solid carrier material as an important formulation variable that can not only maintain the biopharmaceutical performance of the original LBDDS, but also enhance in vivo performance or confer various other advantageous characteristics. Studies available in the literature that exemplify this ability of the solid carrier material to actively influence LBDDS properties and performance have been discussed, and various novel solid carrier materials have been considered to demonstrate the potential gains that come from thinking outside of the box when choosing a solid carrier for LBDDS. Most significantly, recent estimates have suggested 
that up to $70 \%$ of all new drug candidates display poor aqueous solubility, thereby verifying the importance of LBDDS as a strategy to mediate this problem. No solid-state LBDDS have gained marketing approval as yet, but with careful consideration and optimization of formulation variables, we might anticipate faster translation of solid-state LBDDS research to the pharmaceutical marketplace.

\section{ACKNOWLEDGMENTS}

The Australian Research Council (Discovery Grant Scheme, DP120101065), ITEK Pty. Ltd., Bioinnovation South Australia, and the Australian Biotech Ceridia Pty. Ltd. are gratefully acknowledged for research funding and support.

\section{REFERENCES}

1. Humberstone AJ, Charman WN. Lipid-based vehicles for the oral delivery of poorly water soluble drugs. Adv Drug Delivery Rev. 1997;25(1):103-28.

2. Porter CJH, Trevaskis NL, Charman WN. Lipids and lipidbased formulations: optimizing the oral delivery of lipophilic drugs. Nat Rev Drug Discov. 2007;6(3):231-48.

3. Charman WN, Porter CJ, Mithani S, Dressman JB. Physicochemical and physiological mechanisms for the effects of food on drug absorption: the role of lipids and pH. J Pharm Sci. 1997;86(3):26982.

4. Hauss DJ. Oral lipid-based formulations. Adv Drug Delivery Rev. 2007;59(7):667-76.

5. Chakraborty S, Shukla D, Mishra B, Singh S. Lipid-an emerging platform for oral delivery of drugs with poor bioavailability. Eur J Pharm Biopharm. 2009;73(1):1-15.

6. Pouton CW. Lipid formulations for oral administration of drugs: non-emulsifying, self-emulsifying and 'selfmicroemulsifying' drug delivery systems. Eur J Pharm Sci. 2000;11(S2):S93-8.

7. Porter CJH, Pouton CW, Cuine JF, Charman WN. Enhancing intestinal drug solubilisation using lipid-based delivery systems. Adv Drug Delivery Rev. 2008;60(6):673-91.

8. Strickley RG. Currently marketed oral lipid-based dosage forms: drug products and excipients. In: Hauss DJ, editor. Oral lipid-based formulations: enhancing the bioavailability of poorly water-soluble drugs. Drugs and the Pharmaceutical Sciences. 170. New York: Informa Healthcare; 2007. p. 1-31.

9. Kawabata Y, Wada K, Nakatani M, Yamada S, Onoue S. Formulation design for poorly water-soluble drugs based on biopharmaceutics classification system: basic approaches and practical applications. Int J Pharm. 2011;420(1):1-10.

10. Balakrishnan P, Lee B-J, Oh DH, Kim JO, Hong MJ, Jee J-P, et al. Enhanced oral bioavailability of dexibuprofen by a novel solid self-emulsifying drug delivery system (SEDDS). Eur J Pharm Biopharm. 2009;72(3):539-45.

11. Tan A, Rao S, Prestidge CA. Transforming lipid-based oral drug delivery systems into solid dosage forms: an overview of solid carriers, physicochemical properties, and biopharmaceutical performance. Pharm Res. 2013;30(12):2993-3017.

12. Tan A, Martin A, Nguyen T-H, Boyd BJ, Prestidge CA. Hybrid nanomaterials that mimic the food effect: controlling enzymatic digestion for enhanced oral drug absorption. Angew Chem. 2012;124(22):5571-5.

13. Nguyen TH, Tan A, Santos L, Ngo D, Edwards GA, Porter CJ, et al. Silica-lipid hybrid (SLH) formulations enhance the oral bioavailability and efficacy of celecoxib: an in vivo evaluation. J Control Release. 2013;167(1):85-91.

14. Tan A, Simovic S, Davey AK, Rades T, Boyd BJ, Prestidge CA. Silica nanoparticles to control the lipase-mediated digestion of lipid-based oral delivery systems. Mol Pharm. 2010;7(2):522-32.
15. Tan A, Simovic S, Davey AK, Rades T, Prestidge CA. Silicalipid hybrid (SLH) microcapsules: a novel oral delivery system for poorly soluble drugs. J Control Release. 2009;134(1):62-70.

16. Jannin V, Musakhanian J, Marchaud D. Approaches for the development of solid and semi-solid lipid-based formulations. Adv Drug Deliv Rev. 2008;60(6):734-46.

17. Tang B, Cheng G, Gu JC, Xu CH. Development of solid selfemulsifying drug delivery systems: preparation techniques and dosage forms. Drug Discov Today. 2008;13(13-14):606-12.

18. Christensen KL, Pedersen GP, Kristensen HG. Preparation of redispersible dry emulsions by spray drying. Int $\mathrm{J}$ Pharm. 2001;212(2):187-94.

19. Grove M, Mullertz A. Lipid self-microemulsifying drug delivery systems. In: Hauss DJ, editor. Oral lipid-based formulations: enhancing the bioavailability of poorly water-soluble drugs. Drugs and the Pharmaceutical Sciences. 170. New York: Informa Healthcare; 2007. p. 107-27.

20. Simovic S, Ghouchi-Eskandar N, Sinn AM, Losic D, Prestidge CA. Silica materials in drug delivery applications. Curr Drug Discov Technol. 2011;8(3):269-76.

21. Handbook of pharmaceutical excipients [Internet]. Pharmaceutical Press. 2014 [cited 27/05/2015]. Available from: https:// www.medicinescomplete.com/mc/excipients/current/.

22. Barbé C, Bartlett J, Kong L, Finnie K, Lin HQ, Larkin M, et al. Silica particles: a novel drug-delivery system. Adv Mater. 2004;16(21):1959-66.

23. Kresge CT, Leonowicz ME, Roth WJ, Vartuli JC, Beck JS. Ordered mesoporous molecular sieves synthesized by a liquidcrystal template mechanism. Nature. 1992;359(6397):710-2.

24. Vallet-Regi M, Rámila A, del Real RP, Pérez-Pariente J. A new property of MCM-41: drug delivery system. Chem Mater. 2001;13(2):308-11.

25. Tan A, Prestidge CA. Nanostructured silica-lipid hybrid microparticles: a supersaturating carrier for water- and lipid-resistant compounds. Chem Lett. 2012;41:1334-6.

26. Joyce P, Tan A, Whitby CP, Prestidge CA. The role of porous nanostructure in controlling lipase-mediated digestion of lipid loaded into silica particles. Langmuir. 2014;30(10):2779-88.

27. Simovic S, Heard P, Hui H, Song Y, Peddie F, Davey AK, et al. Dry hybrid lipid-silica microcapsules engineered from submicron lipid droplets and nanoparticles as a novel delivery system for poorly soluble drugs. Mol Pharm. 2009;6(3):861-72.

28. Kang JH, Oh DH, Oh Y-K, Yong CS, Choi H-G. Effects of solid carriers on the crystalline properties, dissolution and bioavailability of flurbiprofen in solid self-nanoemulsifying drug delivery system (solid SNEDDS). Eur J Pharm Biopharm. 2012;80(2):289-97.

29. Oh DH, Kang JH, Kim DW, Lee B-J, Kim JO, Yong CS, et al. Comparison of solid self-microemulsifying drug delivery system (solid SMEDDS) prepared with hydrophilic and hydrophobic solid carrier. Int J Pharm. 2011;420(2):412-8.

30. Weerapol Y, Limmatvapirat S, Nunthanid J, Sriamornsak P. Self-nanoemulsifying drug delivery system of nifedipine: impact of hydrophilic-lipophilic balance and molecular structure of mixed surfactants. AAPS PharmSciTech. 2014;15(2):456-64.

31. Van Speybroeck M, Williams HD, Nguyen T-H, Anby MU, Porter $\mathrm{CJH}$, Augustijns P. Incomplete desorption of liquid excipients reduces the in vitro and in vivo performance of self-emulsifying drug delivery systems solidified by adsorption onto an inorganic mesoporous carrier. Mol Pharm. 2012;9(9):2750-60.

32. Williams HD, Van Speybroeck M, Augustijns P, Porter CJ. Lipid-based formulations solidified via adsorption onto the mesoporous carrier Neusilin US2: effect of drug type and formulation composition on in vitro pharmaceutical performance. J Pharm Sci. 2014;103(6):1734-46.

33. Krupa A, Szlęk J, Jany B, Jachowicz R. Preformulation studies on solid self-emulsifying systems in powder form containing magnesium aluminometasilicate as porous carrier. AAPS PharmSciTech. 2015;16(3):623-35.

34. Hansen T, Holm P, Rohde M, Schultz K. In vivo evaluation of tablets and capsules containing spray-dried o/w-emulsions for oral delivery of poorly soluble drugs. Int J Pharm. 2005;293(1-2):203-11.

35. Yi T, Wan J, Xu H, Yang X. Controlled poorly soluble drug release from solid self-microemulsifying formulations with high 
viscosity hydroxypropylmethylcellulose. Eur J Pharm Sci. 2008;34(4-5):274-80.

36. Shah A, Serajuddin AM. Development of solid self-emulsifying drug delivery system (SEDDS) I: use of poloxamer 188 as both solidifying and emulsifying agent for lipids. Pharm Res. 2012;29(10):2817-32.

37. Tran PH-L, Tran TT-D, Piao ZZ, Van Vo T, Park JB, Lim J, et al. Physical properties and in vivo bioavailability in human volunteers of isradipine using controlled release matrix tablet containing self-emulsifying solid dispersion. Int $\mathrm{J}$ Pharm. 2013;450(1-2):79-86.

38. Xu W, Riikonen J, Lehto VP. Mesoporous systems for poorly soluble drugs. Int J Pharm. 2013;453(1):181-97.

39. Narang AS, Chang RK, Hussain MA. Pharmaceutical development and regulatory considerations for nanoparticles and nanoparticulate drug delivery systems. J Pharm Sci. 2013;102(11):3867-82.

40. Gamboa JM, Leong KW. In vitro and in vivo models for the study of oral delivery of nanoparticles. Adv Drug Deliv Rev. 2013;65(6):800-10.

41. Zhao P, Wang L, Sun C, Jiang T, Zhang J, Zhang Q, et al. Uniform mesoporous carbon as a carrier for poorly water soluble drug and its cytotoxicity study. Eur J Pharm Biopharm. 2012;80(3):535-43.

42. Volodkin D. CaCO3 templated micro-beads and -capsules for bioapplications. Adv Colloid Interface Sci. 2014;206C:437-54.

43. Forsgren J, Frykstrand S, Grandfield K, Mihranyan A, Strømme M. A template-free, ultra-adsorbing, high surface area carbonate nanostructure. PLoS ONE. 2013;8(7):1-8.

44. Frykstrand S, Forsgren J, Mihranyan A, Strømme M. On the pore forming mechanism of Upsalite, a micro- and mesoporous magnesium carbonate. Microporous Mesoporous Mater. 2014;190:99-104.

45. Zhang P, Forsgren J, Stromme M. Stabilisation of amorphous ibuprofen in Upsalite, a mesoporous magnesium carbonate, as an approach to increasing the aqueous solubility of poorly soluble drugs. Int J Pharm. 2014;472(1-2):185-91.

46. Zhang P, Gómez De La Torre TZ, Forsgren J, Bergström C, Strømme M. Diffusion-controlled drug release from the mesoporous magnesium carbonate Upsalite ${ }^{\circledR}$. J Pharm Sci. 2015.

47. Aguzzi C, Cerezo P, Viseras C, Caramella C. Use of clays as drug delivery systems: possibilities and limitations. Appl Clay Sci. 2007;36(1-3):22-36.

48. Bi X, Zhang H, Dou L. Layered double hydroxide-based nanocarriers for drug delivery. Pharmaceutics. 2014;6(2):298-332.

49. Rodrigues A, Emeje M. Recent applications of starch derivatives in nanodrug delivery. Carbohydr Polym. 2012;87(2):987-94.

50. Niu X, Wan L, Hou Z, Wang T, Sun C, Sun J, et al. Mesoporous carbon as a novel drug carrier of fenofibrate for enhancement of the dissolution and oral bioavailability. Int J Pharm. 2013;452(1-2):382-9.

51. Shen S-C, Ng WK, Chia L, Dong Y-C, Tan RBH. Preparation and application of monodispersed mesoporous submicron carbon particles as a drug carrier. Powder Technol. 2014:261:241-9.

52. Zhang $\mathrm{Y}$, Wang $\mathrm{H}$, Gao $\mathrm{C}, \mathrm{Li} \mathrm{X}, \mathrm{Li}$ L. Highly ordered mesoporous carbon nanomatrix as a new approach to improve the oral absorption of the water-insoluble drug, simvastatin. Eur J Pharm Sci. 2013;49(5):864-72.

53. Zhang Y, Zhi Z, Li X, Gao J, Song Y. Carboxylated mesoporous carbon microparticles as new approach to improve the oral bioavailability of poorly water-soluble carvedilol. Int J Pharm. 2013;454(1):403-11.

54. Zhao P, Jiang H, Jiang T, Zhi Z, Wu C, Sun C, et al. Inclusion of celecoxib into fibrous ordered mesoporous carbon for enhanced oral bioavailability and reduced gastric irritancy. Eur J Pharm Sci. 2012;45(5):639-47.

55. Zhang Y, Zhao Q, Zhu W, Zhang L, Han J, Lin Q, et al. Synthesis and evaluation of mesoporous carbon/lipid bilayer nanocomposites for improved oral delivery of the poorly watersoluble drug. Nimodipine Pharm Res. 2015;32(7):2372-83.

56. Forsgren J, Andersson M, Nilsson P, Mihranyan A. Mesoporous calcium carbonate as a phase stabilizer of amorphous celecoxib-an approach to increase the bioavailability of poorly soluble pharmaceutical substances. Adv Healthc Mater. 2013;2(11):1469-76.

57. Preisig D, Haid D, Varum FJO, Bravo R, Alles R, Huwyler J, et al. Drug loading into porous calcium carbonate microparticles by solvent evaporation. Eur J Pharm Biopharm. 2014;87(3):548-58.

58. Joshi GV, Kevadiya BD, Patel HA, Bajaj HC, Jasra RV. Montmorillonite as a drug delivery system: intercalation and in vitro release of timolol maleate. Int J Pharm. 2009:374(12):53-7.

59. Oh YJ, Choi G, Choy YB, Park JW, Park JH, Lee HJ, et al. Aripiprazole-montmorillonite: a new organic-inorganic nanohybrid material for biomedical applications. Chemistry. 2013;19(15):4869-75.

60. Baek M, Choy JH, Choi SJ. Montmorillonite intercalated with glutathione for antioxidant delivery: synthesis, characterization, and bioavailability evaluation. Int J Pharm. 2012;425(1-2):29-34.

61. Dong $\mathrm{Y}, \mathrm{Ng} \mathrm{WK}, \mathrm{Hu} \mathrm{J}$, Shen S, Tan RB. Clay as a matrix former for spray drying of drug nanosuspensions. Int J Pharm. 2014;465(1-2):83-9.

62. Berber MR, Hafez IH, Minagawa K, Mori T, Tanaka M. Nanocomposite formulation system of lipid-regulating drugs based on layered double hydroxide: synthesis, characterization and drug release properties. Pharm Res. 2010;27(11):2394-401.

63. Berber MR, Minagawa K, Katoh M, Mori T, Tanaka M. Nanocomposites of 2-arylpropionic acid drugs based on $\mathrm{Mg}_{-}$ Al layered double hydroxide for dissolution enhancement. Eur J Pharm Sci. 2008;35(4):354-60.

64. Choi G, Lee JH, Oh YJ, Choy YB, Park MC, Chang HC, et al. Inorganic-polymer nanohybrid carrier for delivery of a poorlysoluble drug, ursodeoxycholic acid. Int J Pharm. 2010;402(12):117-22.

65. Wu C, Wang Z, Zhi Z, Jiang T, Zhang J, Wang S. Development of biodegradable porous starch foam for improving oral delivery of poorly water soluble drugs. Int J Pharm. 2011;403(1-2):162-9.

66. Ali MT, Fule R, Sav A, Amin P. Porous starch: a novel carrier for solubility enhancement of carbamazepine. AAPS PharmSciTech. 2013;14(3):919-26.

67. Zhang Z, Huang J, Jiang S, Liu Z, Gu W, Yu H, et al. Porous starch based self-assembled nano-delivery system improves the oral absorption of lipophilic drug. Int J Pharm. 2013;444(1-2):162-8.

68. Saha D, Warren KE, Naskar AK. Soft-templated mesoporous carbons as potential materials for oral drug delivery. Carbon. 2014;71:47-57.

69. Wang X, Liu P, Tian Y, Zang L. Novel synthesis of Fecontaining mesoporous carbons and their release of ibuprofen. Microporous Mesoporous Mater. 2011;145(1-3):98-103.

70. Gustafsson H, Thörn C, Holmberg K. A comparison of lipase and trypsin encapsulated in mesoporous materials with varying pore sizes and $\mathrm{pH}$ conditions. Colloids Surf B: Biointerfaces. 2011;87(2):464-71.

71. Gustafsson H, Johansson EM, Barrabino A, Odén M, Holmberg K. Immobilization of lipase from Mucor miehei and Rhizopus oryzae into mesoporous silica-the effect of varied particle size and morphology. Colloids Surf B: Biointerfaces. 2012;100:22-30.

72. Gao Y, Zhu W, Liu J, Di D, Chang D, Jiang T, et al. A geometric pore adsorption model for predicting the drug loading capacity of insoluble drugs in mesoporous carbon. Int J Pharm. 2015;485(1-2):25-30.

73. Wang T, Zou M, Jiang H, Ji Z, Gao P, Cheng G. Synthesis of a novel kind of carbon nanoparticle with large mesopores and macropores and its application as an oral vaccine adjuvant. Eur J Pharm Sci. 2011;44(5):653-9.

74. Zhang Y, Wang H, Li C, Sun B, Wang Y, Wang S, et al. A novel three-dimensional large-pore mesoporous carbon matrix as a potential nanovehicle for the fast release of the poorly watersoluble drug, celecoxib. Pharm Res. 2014;31(4):1059-70.

75. Martindale: the complete drug reference [Internet]. Pharmaceutical Press. 2015 [cited 29/05/2015]. Available from: https:// www.medicinescomplete.com/mc/martindale/current/. 
76. Qiu N, Yin H, Ji B, Klauke N, Glidle A, Zhang Y, et al. Calcium carbonate microspheres as carriers for the anticancer drug camptothecin. Mater Sci Eng C. 2012;32(8):2634-40.

77. Svenskaya Y, Parakhonskiy B, Haase A, Atkin V, Lukyanets E, Gorin D, et al. Anticancer drug delivery system based on calcium carbonate particles loaded with a photosensitizer. Biophys Chem. 2013;182:11-5.

78. Peng $\mathrm{H}, \mathrm{Li} \mathrm{K}$, Wang $\mathrm{T}$, Wang $\mathrm{J}$, Wang $\mathrm{J}$, Zhu $\mathrm{R}$, et al. Preparation of hierarchical mesoporous $\mathrm{CaCO} 3$ by a facile binary solvent approach as anticancer drug carrier for etoposide. Nanoscale Res Lett. 2013;8(1):1-11.

79. Volodkin D, von Klitzing $\mathrm{R}$, Möhwald H. Pure protein microspheres by calcium carbonate templating. Angew Chem. 2010;122(48):9444-7.

80. Parakhonskiy BV, Haase A, Antolini R. Sub-micrometer vaterite containers: synthesis, substance loading, and release. Angew Chem Int Ed. 2012;51(5):1195-7.

81. Wei W, Ma G-H, Hu G, Yu D, McLeish T, Su Z-G, et al. Preparation of hierarchical hollow $\mathrm{CaCO} 3$ particles and the application as anticancer drug carrier. J Am Chem Soc. 2008;130(47):15808-10.

82. Stirnimann T, Di Maiuta N, Gerard DE, Alles R, Huwyler J, Puchkov M. Functionalized calcium carbonate as a novel pharmaceutical excipient for the preparation of orally dispersible tablets. Pharm Res. 2013;30(7):1915-25.

83. Stirnimann T, Atria S, Schoelkopf J, Gane PA, Alles R, Huwyler J, et al. Compaction of functionalized calcium carbonate, a porous and crystalline microparticulate material with a lamellar surface. Int J Pharm. 2014;466(1-2):266-75.

84. Sigma-Aldrich. Mesostructured silica MCM-41 type (hexagonal) 2015 [09/06/2015]. Available from: http://www.sigmaaldrich.com/ catalog/product/aldrich/643645?lang=en\&region=AU.

85. Viseras C, Cerezo P, Sanchez R, Salcedo I, Aguzzi C. Current challenges in clay minerals for drug delivery. Appl Clay Sci. 2010;48(3):291-5.

86. Rodrigues LA, Figueiras A, Veiga F, de Freitas RM, Nunes LC, da Silva Filho EC, et al. The systems containing clays and clay minerals from modified drug release: a review. Colloids Surf B: Biointerfaces. 2013;103:642-51.

87. Zheng JP, Luan L, Wang HY, Xi LF, Yao KD. Study on ibuprofen/montmorillonite intercalation composites as drug release system. Appl Clay Sci. 2007:36:297-301.

88. Meng N, Zhou NL, Zhang SQ, Shen J. Controlled release and antibacterial activity chlorhexidine acetate (CA) intercalated in montmorillonite. Int J Pharm. 2009;382(1-2):45-9.

89. Lagaly G, Reese M, Abend S. Smectites as colloidal stabilizers of emulsions: I. Preparation and properties of emulsions with smectites and nonionic surfactants. Appl Clay Sci. 1999;14(13):83-103.

90. Guillot S, Bergaya F, de Azevedo C, Warmont F, Tranchant J-F. Internally structured Pickering emulsions stabilized by clay mineral particles. J Colloid Interface Sci. 2009;333(2):563-9.

91. Gunawan P, Xu R. Direct control of drug release behavior from layered double hydroxides through particle interactions. J Pharm Sci. 2008;97(10):4367-78.
92. Rives V, Del Arco M, Martin C. Layered double hydroxides as drug carriers and for controlled release of non-steroidal antiinflammatory drugs (NSAIDs): a review. J Control Release. 2013;169(1-2):28-39.

93. Rives V, del Arco M, Martín C. Intercalation of drugs in layered double hydroxides and their controlled release: a review. Appl Clay Sci. 2014;88-89:239-69.

94. Parello ML, Rojas R, Giacomelli CE. Dissolution kinetics and mechanism of Mg-Al layered double hydroxides: a simple approach to describe drug release in acid media. J Colloid Interface Sci. 2010;351(1):134-9.

95. Wang J, Yang F, Tan J, Liu G, Xu J, Sun D. Pickering emulsions stabilized by a lipophilic surfactant and hydrophilic platelike particles. Langmuir. 2010;26(8):5397-404.

96. Zhang N, Zhang L, Sun D. Influence of emulsification process on the properties of Pickering emulsions stabilized by layered double hydroxide particles. Langmuir. 2015;31(16):4619-26.

97. Yang F, Liu S, Xu J, Lan Q, Wei F, Sun D. Pickering emulsions stabilized solely by layered double hydroxides particles: the effect of salt on emulsion formation and stability. J Colloid Interface Sci. 2006:302(1):159-69.

98. Rahman MBA, Basri M, Hussein MZ, Idris MNH, Rahman RNZRA, Salleh AB. Immobilisation of lipase from Candida rugosa on layered double hydroxides of $\mathrm{Mg} / \mathrm{Al}$ and its nanocomposite as biocatalyst for the synthesis of ester. Catal Today. 2004;93-95:405-10.

99. Rahman MBA, Zaidan UH, Basri M, Hussein MZ, Rahman RNZRA, Salleh AB. Enzymatic synthesis of methyl adipate ester using lipase from Candida rugosa immobilised on $\mathrm{Mg}, \mathrm{Zn}$ and $\mathrm{Ni}$ of layered double hydroxides (LDHs). J Mol Catal B Enzym. 2008;50(1):33-9.

100. Ge Z, Zhang X-X, Gan L, Gan Y. Redispersible, dry emulsion of lovastatin protects against intestinal metabolism and improves bioavailability. Acta Pharmacol Sin. 2008;29(8):990-7.

101. Abdelbary G, Amin M, Salah S. Self nano-emulsifying simvastatin based tablets: design and in vitro/in vivo evaluation. Pharm Dev Technol. 2013;18(6):1294-304.

102. Mitragotri S, Anderson DG, Chen X, Chow EK, Ho D, Kabanov AV, et al. Accelerating the translation of nanomaterials in biomedicine. ACS Nano. 2015;9(7):6644-54.

103. Gencoglu MF, Spurri A, Franko M, Chen J, Hensley DK, Heldt CL, et al. Biocompatibility of soft-templated mesoporous carbons. ACS Appl Mater Interfaces. 2014;6(17):1506877.

104. Karavasili C, Amanatiadou EP, Sygellou L, Giasafaki DK, Steriotis TA, Charalambopoulou GC, et al. Development of new drug delivery system based on ordered mesoporous carbons: characterisation and cytocompatibility studies. J Mater Chem B. 2013;1:3167-74.

105. Wan L, Wang X, Zhu W, Zhang C, Song A, Sun C, et al. Folatepolyethyleneimine functionalized mesoporous carbon nanoparticles for enhancing oral bioavailability of paclitaxel. Int $\mathrm{J}$ Pharm. 2015;484(1-2):207-17. 